\title{
Applying the transtheoretical model to eating behaviour change: challenges and opportunities
}

\author{
Caroline C. Horwath
}

\begin{abstract}
This review provides a rigorous investigation of the question of whether the transtheoretical model (TTM) (or stages of change model) is applicable to eating behaviour change. The TTM is currently the most popular of a number of stage theories being used to examine health behaviour change. Stage theories specify an ordered set of 'stages of readiness to change' into which people can be classified and identify the factors that can facilitate movement from one stage to the next. If eating behaviour change follows a stage process, then nutritionists could identify the predominant stage or stages in a population and focus resources on those issues most likely to move people to the next stage (e.g. from no intention of changing, to thinking about changing). In addressing this question, the review draws on the defining characteristics of stage theories as clarified by Weinstein et al. (1998), provides an in-depth coverage of methodological considerations, and a detailed summary table of dietary studies applying the TTM. Specific recommendations are made for improving the accuracy of dietary stage classifications. Among the key conclusions are: (1) dietary studies using the TTM have been hampered by a focus on nutritional outcomes such as dietary fat reduction, rather than clearly understood food behaviours (e.g. five servings of fruit and vegetables per day); (2) accurate stage classification systems are possible for food-based goals, but major misclassification problems occur with nutrient-based goals; (3) observation of an association between stage and dietary intake is not sufficient to demonstrate the validity of the model for dietary behaviour; (4) there is a need for valid questionnaires to measure all aspects of the TTM, and more research on the whole model, particularly the 'processes of change', rather than on single constructs such as 'stage'; (5) cross-sectional studies generally support the predicted patterns of between-stage differences in decisional balance, self-efficacy, and processes of change; (6) studies which test the key hypothesis that different factors are important in distinguishing different stages are rare, as are prospective studies and stage-matched interventions. Only such studies can conclusively determine whether the TTM is applicable to eating behaviour. Since the ultimate test of the TTM will be the effectiveness of stage-matched dietary interventions, the review ends by exploring the requirements for such studies.
\end{abstract}

Transtheoretical model: Stage theories: Behaviour change: Food choice

\footnotetext{
Abbreviation: TTM, transtheoretical model.

Corresponding author: Dr Caroline C. Horwath, fax +03 479 7958, email caroline.horwath@ stonebow. otago.ac.nz
} 


\section{Introduction}

Efforts to prevent disease and to promote healthy eating habits are most likely to succeed if based on an understanding of factors influencing food choice and an appreciation of established theory and research on changing health behaviour (Glanz \& Rimer, 1997). Social and clinical psychology provide several theories which can facilitate our understanding of psychosocial determinants of dietary behaviour (Glanz \& Eriksen, 1993). Amongst the most familiar theories and models applied by health behaviour researchers are: social learning theory or social cognitive theory (Bandura, 1986), the theory of planned behaviour (Ajzen \& Madden, 1986), the health belief model (Janz \& Becker, 1984), consumer information processing theory (Bettman, 1979) and the stages of change (or transtheoretical) model (Prochaska et al. 1992a). All but the last of these models can be seen as continuum theories, in which variables influencing behaviour are combined in a prediction equation indicating, along a continuum, the probability that an individual will perform the behaviour (Weinstein et al. 1998). The manner in which the predictor variables combine to influence behaviour is assumed to be the same for everyone. Stage theories, on the other hand, assume that predictor variables will influence different people in different ways.

Stage theories are increasingly being used to examine health behaviour change. The transtheoretical model (TTM), although currently the most popular stage model in health psychology, is by no means the only stage model. Other stage theories include: the precaution adoption process model (Weinstein \& Sandman, 1992), the health action process approach (Schwarzer, 1992), and models focusing on delay in seeking medical care (Safer et al. 1979).

Stage theories specify an ordered set of categories into which people can be classified, and identify the factors that can induce transitions from one category to the next (Weinstein et al. 1998). On the basis of a stage theory, the predominant stage or stages in a population can be identified, and resources targeted towards those issues most likely to move people to the next stage. Thus treatments may be matched to individuals because people in different stages have different needs.

Weinstein et al. (1998) have recently clarified the defining characteristics of stage theories. A stage theory requires: (1) an accurate classification system for assigning each individual to only one stage; (2) a specified sequence of stages followed by a majority of people (although other paths to action are possible and people do not need to spend a fixed or minimum length of time in any stage); (3) that people at the same stage face similar issues, and thus can be influenced by similar interventions; and, most importantly, (4) that different factors are important in producing transitions at different stages, or in other words, that people at different stages face different barriers to change. Although the precaution adoption process model and TTM differ in the number of stages specified (seven and five respectively), both distinguish people who have not yet decided to change their behaviour, those who have decided to change, and those already performing the new behaviour.

If eating behaviour change can indeed be described by a stage theory, we need not only to be able to classify people into different stages of readiness to alter their dietary habits, but also to demonstrate that different barriers are more important, and different interventions more effective, at the different stages. Demonstration of the usefulness of the TTM for promoting dietary change requires that its predictions are carefully tested for specific eating behaviours. This review explores the evidence currently available to support use of this model for dietary change. It goes beyond previous reviews of dietary applications of the model (Sigman-Grant, 1996; Ni Mhurchu et al. 1997) by providing an in-depth and comprehensive coverage of methodological issues and intervention considerations and as such will be of value to both TTM 


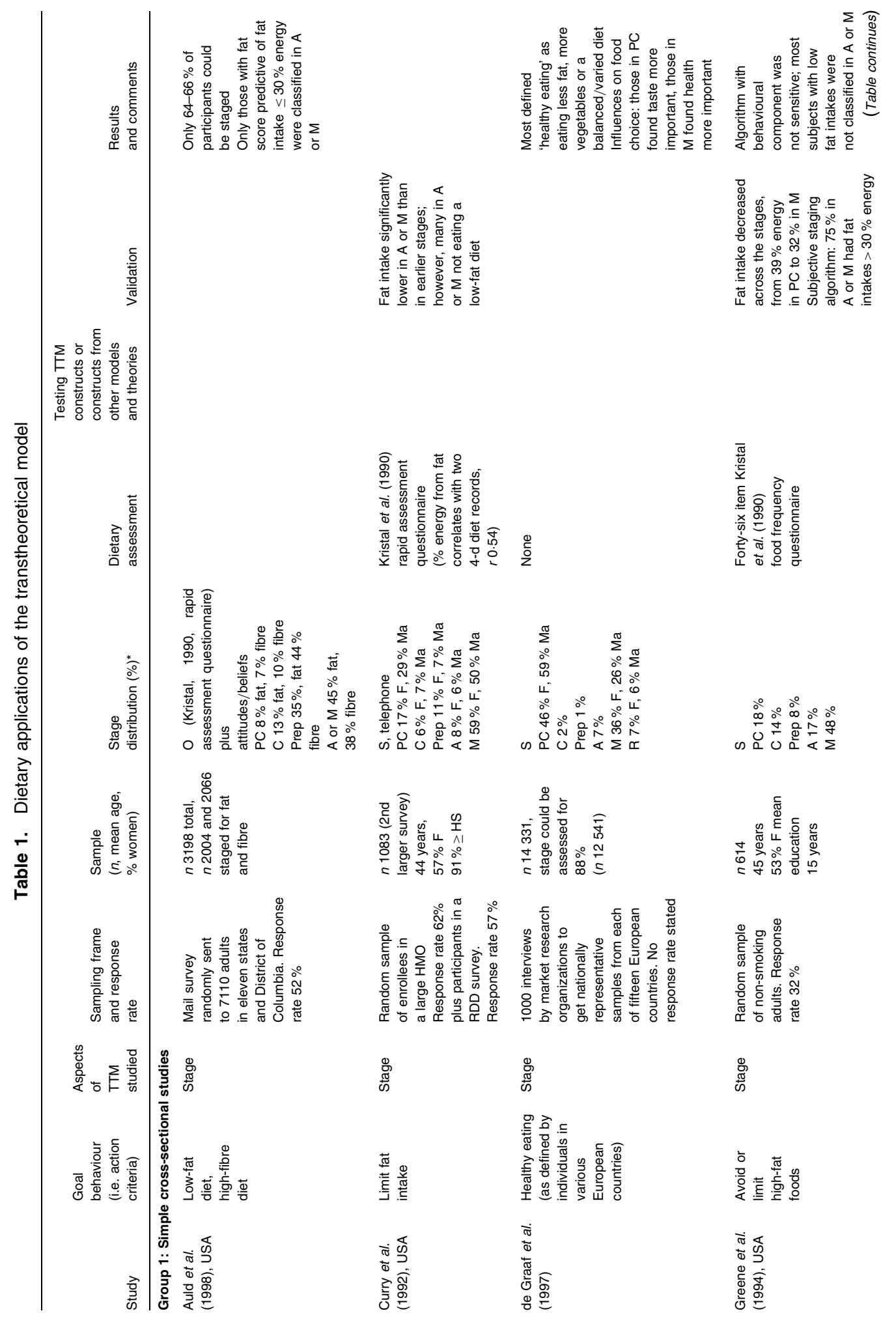




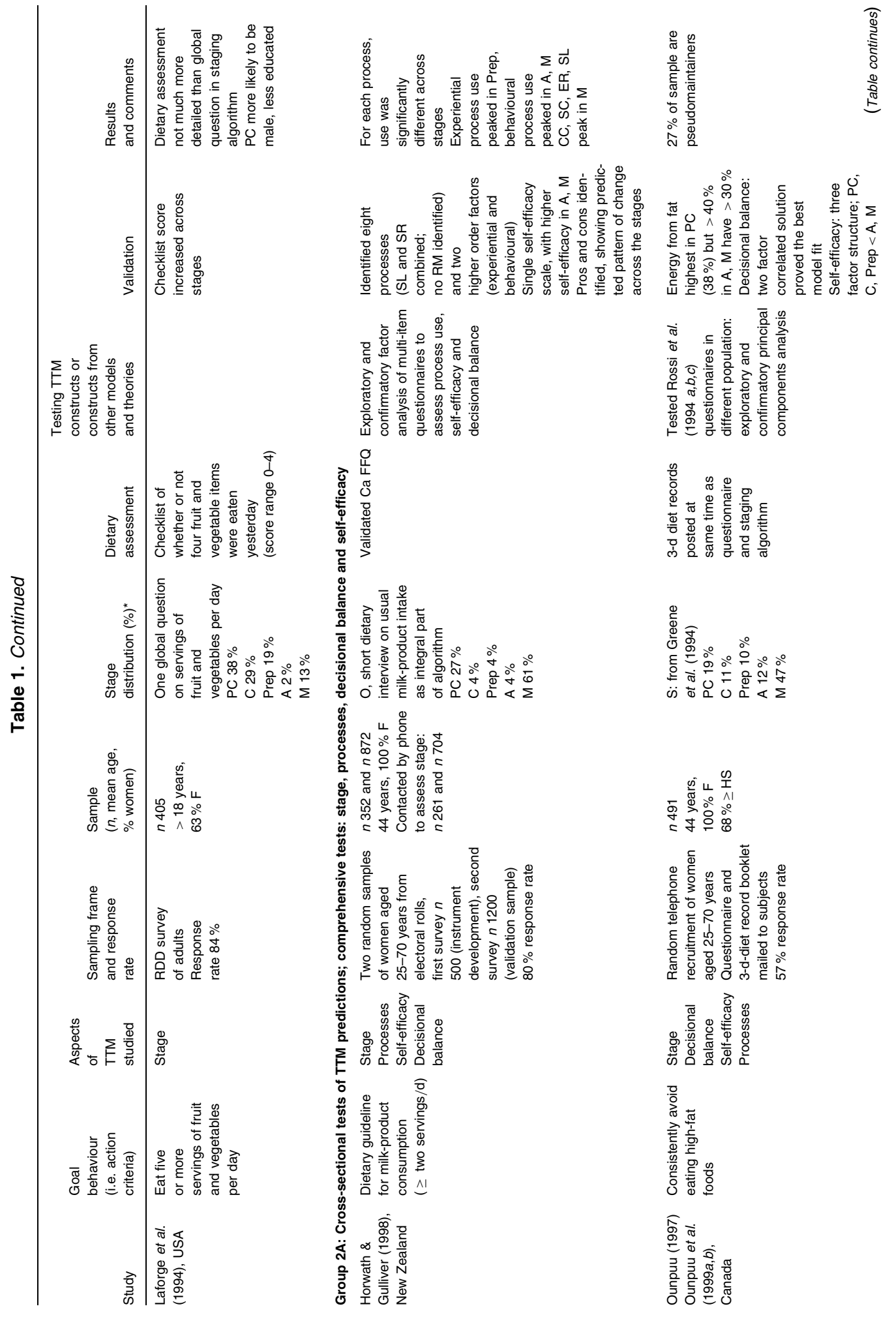




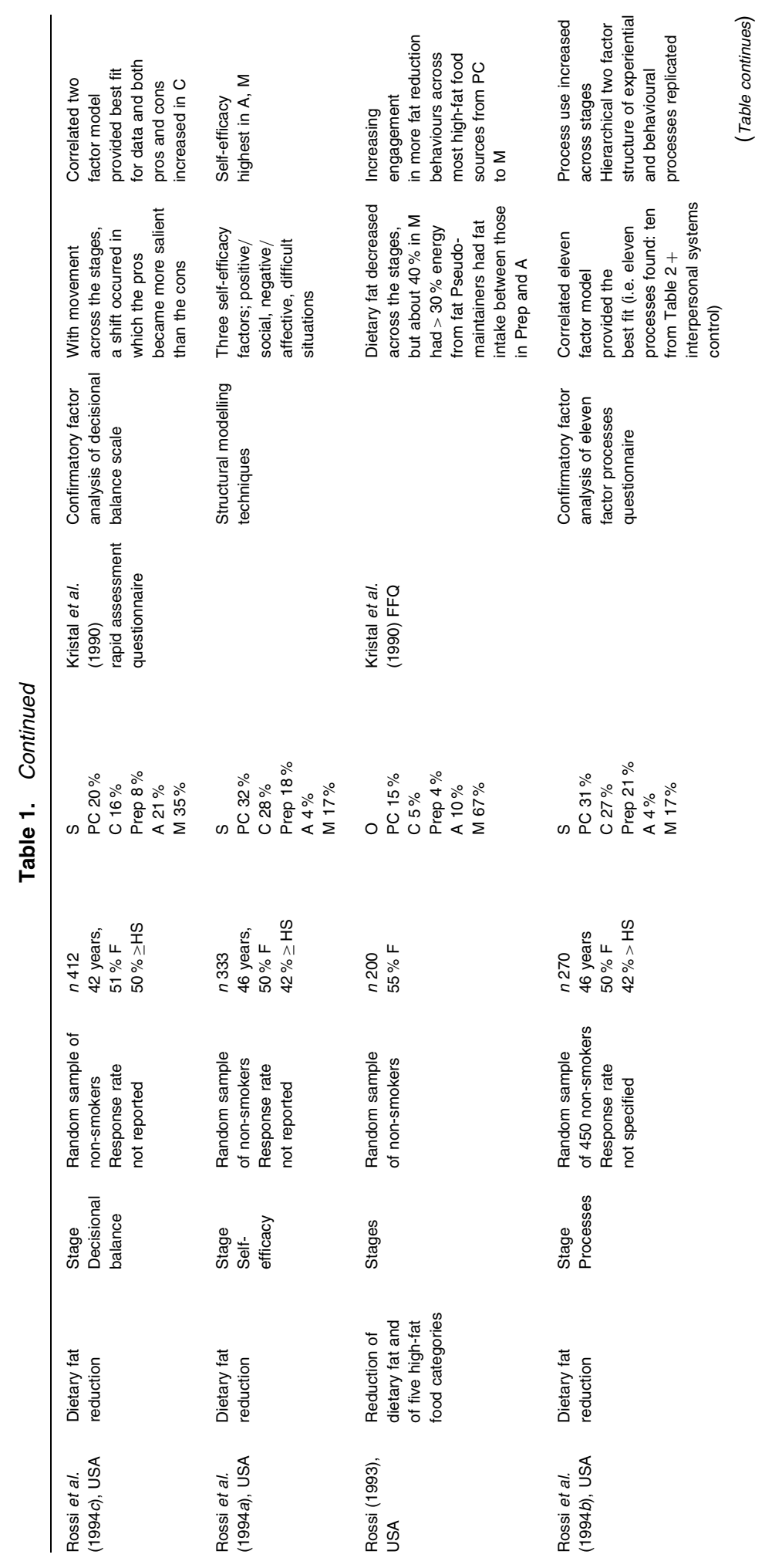




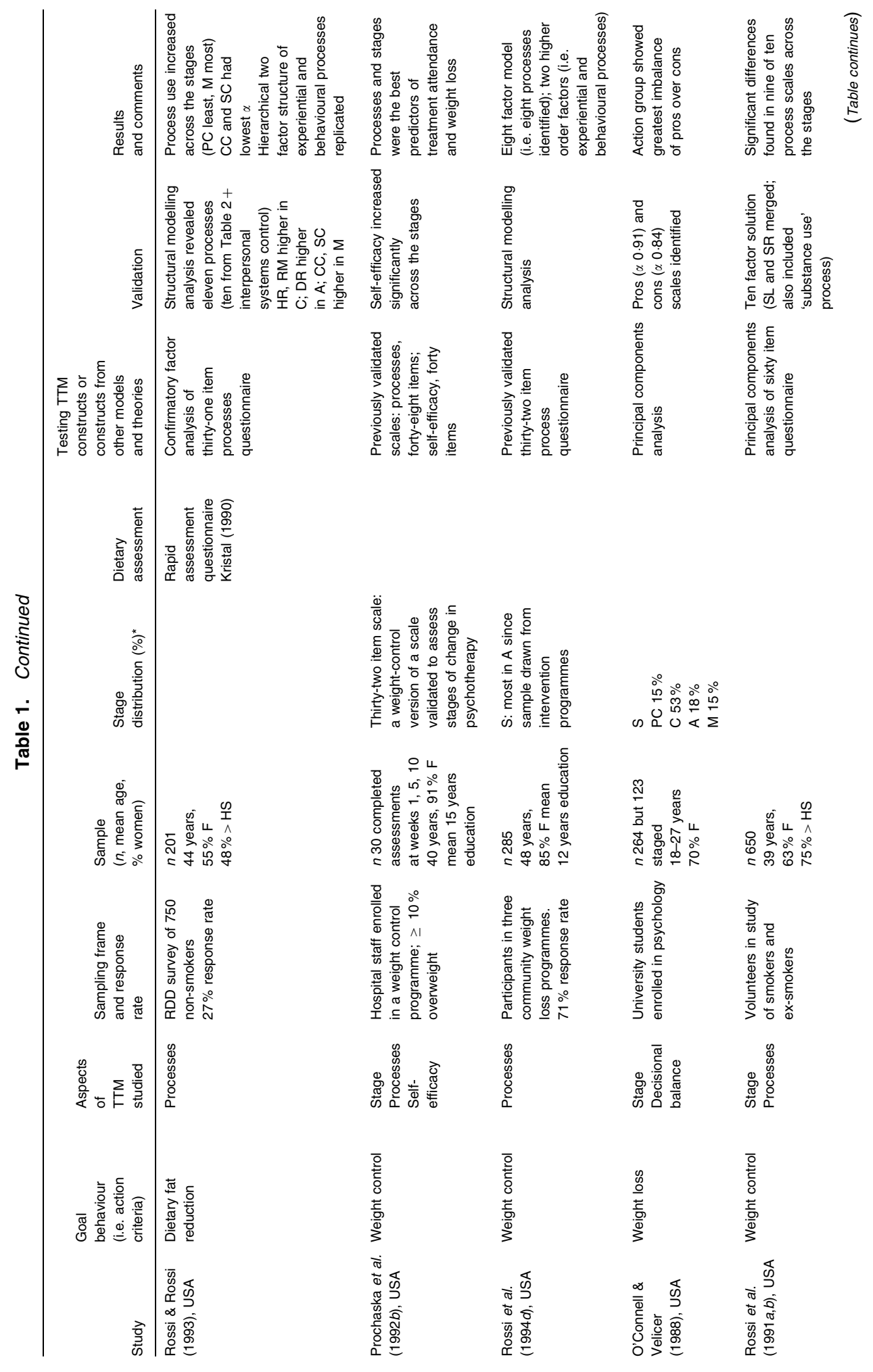




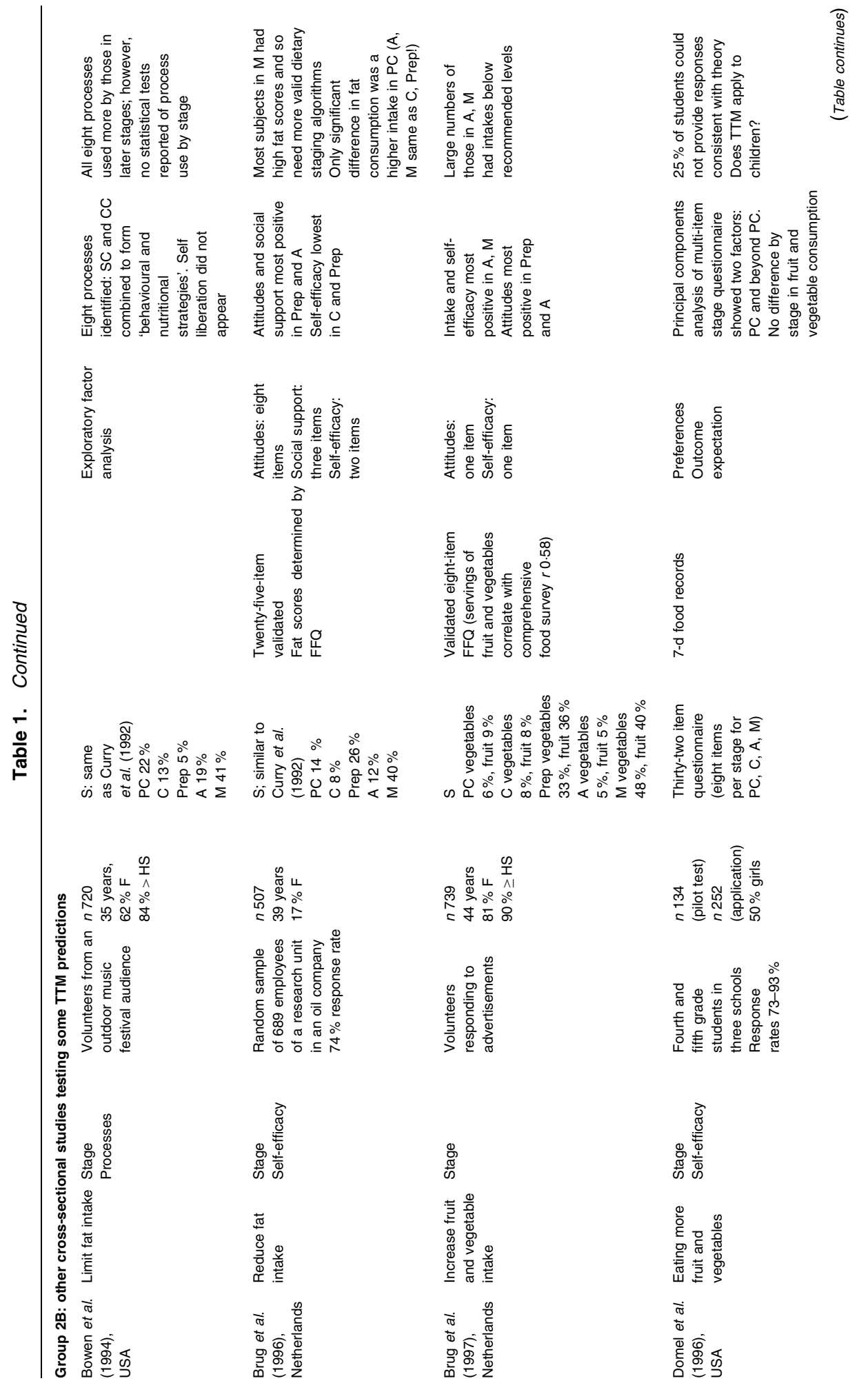




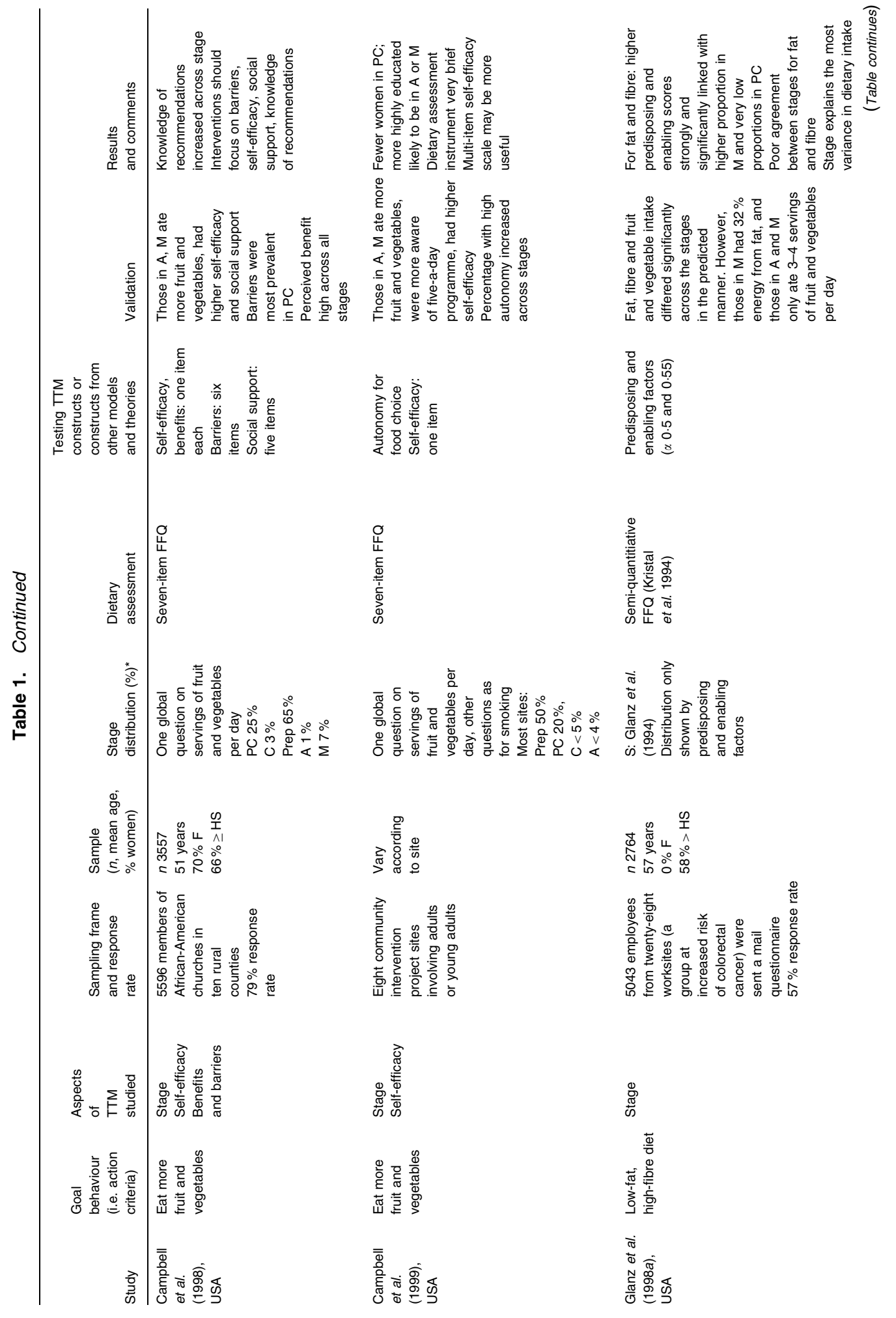




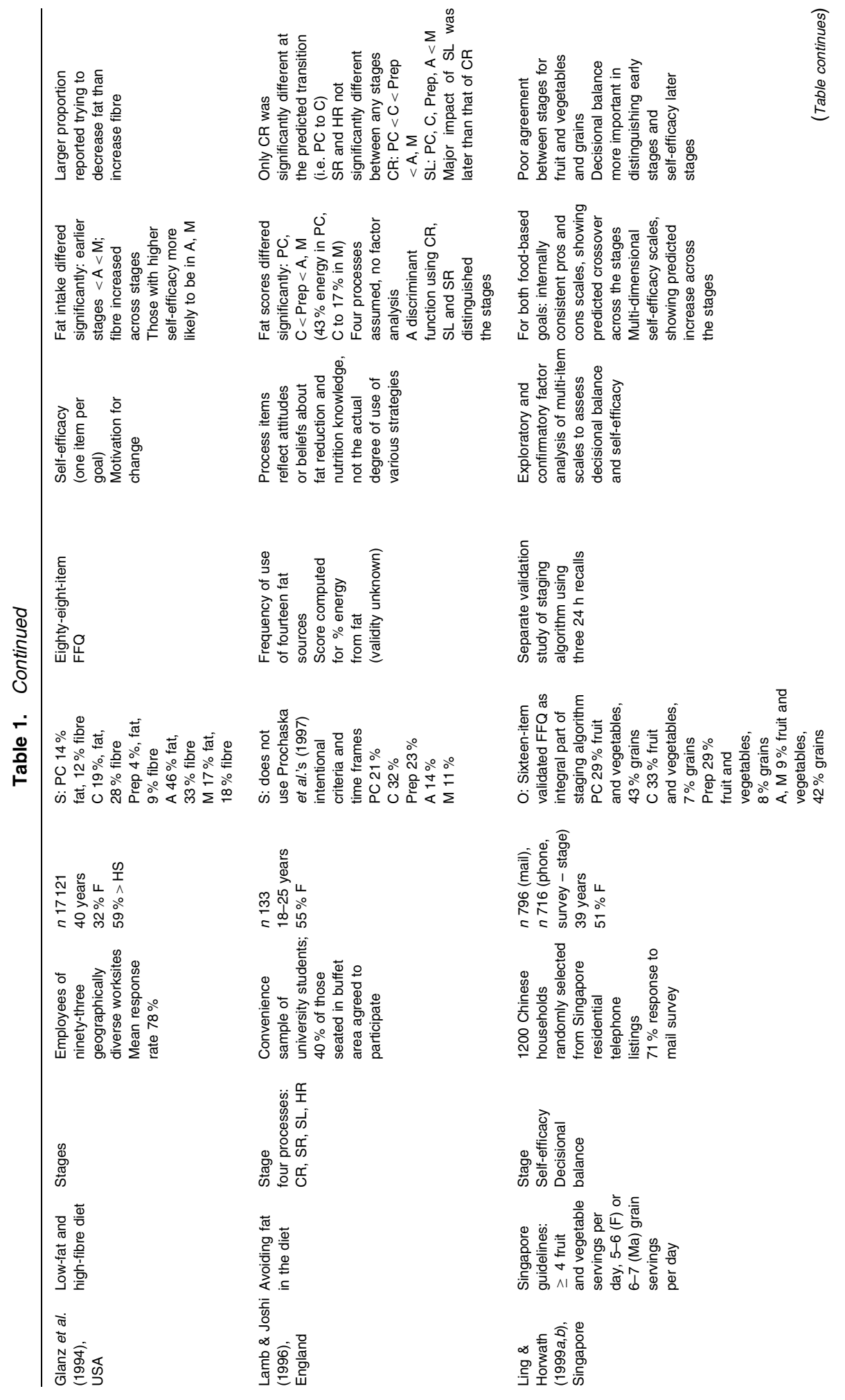




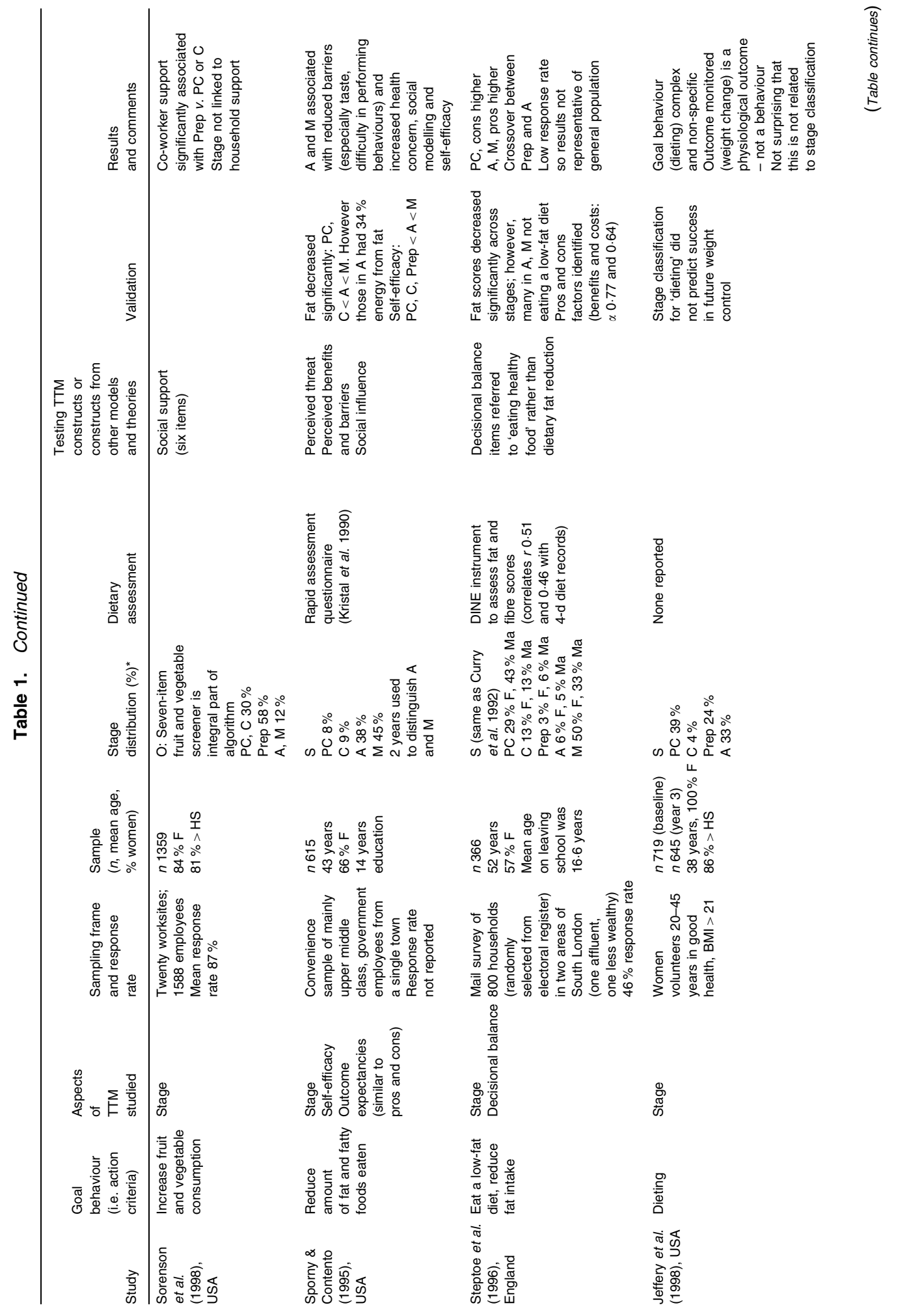




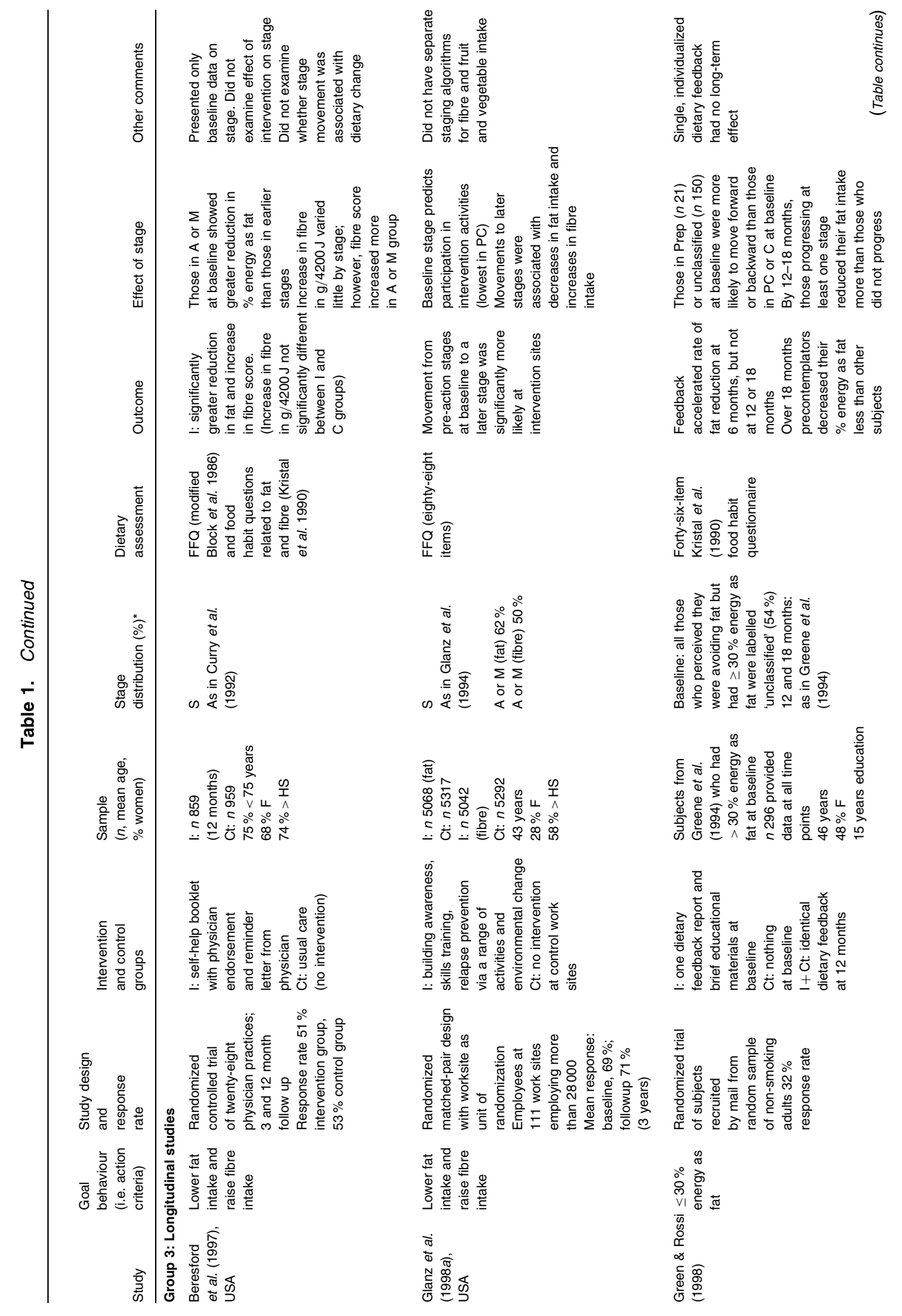




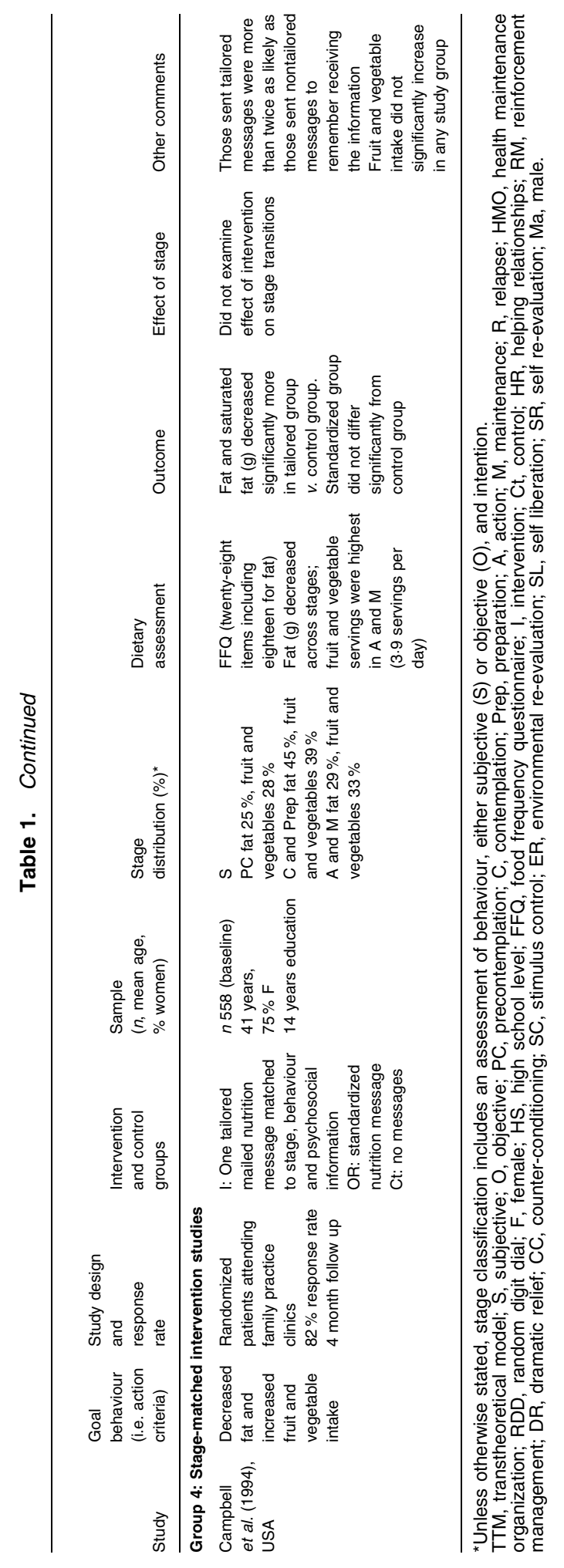


researchers and practitioners. The two previous reviews have focused largely on stage classification, and included tables summarizing six to seven dietary studies. In this present review, Table 1 summarizes thirty-four dietary studies, grouped according to the broad approach taken to test the validity of the model for dietary change. Many of the studies providing the most comprehensive tests of TTM predictions (Table 1: group 2A and group 3) have been reported since the other reviews were published.

\section{Outline of the transtheoretical model}

Although originally developed by Prochaska and DiClemente around 1980 to examine smoking cessation (Prochaska, 1979; DiClemente \& Prochaska, 1982), the TTM has since been applied to a wide range of health behaviours from sunscreen and condom use, to exercise adoption, mammography screening and quitting cocaine (Prochaska et al. 1994). Applications include cessation and acquisition behaviours, as well as addictive and non-addictive behaviours.

\section{Classification system}

People are assigned to one of five stages on the basis of their behaviour and current intentions for future action (Prochaska et al. 1997). Using the example of smoking cessation, a precontemplator is a smoker who has no intention of quitting in the foreseeable future (operationalized as the next 6 months). At this stage, people tend to avoid thinking, talking or reading about the problem behaviour, and in fact, see more benefits than disadvantages to continuing to behave in the same way. Other theories have characterized such people as resistant or unmotivated, or as not ready for health promotion programmes. Traditional health promotion programmes have not been designed to match the needs of precontemplators, or to speak in a language that is relevant to them.

A contemplator is a smoker who is thinking about quitting sometime in the next 6 months, but is not planning to quit in the next month. Contemplators tend to be acutely aware of arguments both for and against changing, and the profound ambivalence which can result may keep people stuck at this stage for long periods (Rossi et al. 1995b). These people are also not ready for traditional action-oriented programmes. Preparation indicates that the person intends to take action within the next month and has made some movement towards action (at least one unsuccessful $24 \mathrm{~h}$ quit attempt in the past year). These individuals have a plan of action, and perceive the benefits of changing as outweighing the costs. Those in preparation are the ones for whom action-oriented programmes are most appropriate.

Action involves successfully altering overt behaviour (i.e. quitting smoking) for anywhere between $1 \mathrm{~d}$ and 6 months. This model makes an important distinction between 'action', which is observable, or overt behaviour change, and other modifications of behaviour. Prochaska $e t$ al. (1997) specify that in order to be classified in action, people must attain the criterion that scientists agree is sufficient to reduce disease risk (e.g. total smoking abstinence, consuming less than $30 \%$ energy as fat). Action is the least stable stage and tends to have the highest risk for relapse. After 6 months a person is said to have reached maintenance, the stage in which people work to prevent relapse. Those in maintenance are less tempted to relapse and increasingly confident that they can continue their changes. For smoking and other addictive behaviours, a stage may eventually be reached where there is no temptation to relapse in any situation ('termination'), and it is as though the problem behaviour never existed. For smoking, this typically takes approximately 5 years. 
It is important to note that the time frames used to distinguish the stages are somewhat arbitrary. Relapse curves and use of change strategies (Prochaska \& DiClemente, 1983) provide support for the action and maintenance time frames for smoking cessation and other addictive behaviours. However, these same time frames have generally been assumed, in the absence of supporting evidence, to be relevant to all health behaviours. It may well be easier to identify the time elapsed since a major event such as quitting smoking, than to estimate the number of months for which multiple changes to eating behaviour have been followed (Greene \& Rossi, 1998). Furthermore, for behaviours undertaken infrequently (such as mammography screening), different time frames are more appropriate.

Progression through the stages is primarily forward and sequential; however, it is neither inevitable or irreversible. Some people endlessly think about changing, without ever acting ('chronic contemplators'). Relapse to earlier stages can occur, so that repeated change attempts and relapses can produce a spiral-like progression through the stages (Prochaska et al. 1992a). Longitudinal studies have shown that behaviour change is not a linear movement through the stages, but instead can be either progressive, regressive, spiralling or static (Prochaska et al. 1992a). Research on smokers indicates that, on average, self-changers make three to four quit attempts before successful cessation is achieved (Prochaska, 1991).

Stage distributions for random samples of smokers are typically: $40 \%$ precontemplation, $40 \%$ contemplation and $20 \%$ preparation (Velicer et al. 1995) and there are some data to support similar distributions for people performing other high-risk behaviours (Rossi, 1992a).

\section{Other constructs of the model}

Despite the great popularity of this model over several years, many studies applying it to behaviours other than smoking have been restricted to examination of the stage classification scheme. The creation of stages and examination of stage characteristics, however, is insufficient to test the validity of a stage model. Stage is just one variable in the TTM. The model also specifies many factors which produce transitions between the stages (processes of change), as well as outcome measures that can be used to monitor success at different stages (self-efficacy (DiClemente, 1981) and decisional balance (Velicer et al. 1985)). Here the model integrates key constructs from different theoretical models. The change that occurs at different stages is qualitatively different, requiring different cognitive, emotional and behavioural activities. Thus different outcome variables can be used to monitor success at the different stages.

Outcome measures. Self-efficacy (confidence to perform the new behaviour) and decisional balance (relative importance of the perceived pros and cons of adopting the new behaviour) constructs are shared by a number of continuum theories (e.g. social learning theory, theory of planned behaviour, health belief model). The pros and cons of change are the individual's perceptions of the actual consequences of changing high-risk behaviours. In the TTM, self-efficacy is conceptualized not only as confidence in ability to change the risk behaviour, but also as temptation to continue the risk behaviour.

Smoking cessation research shows that self-efficacy improves and temptation declines with progression across the stages (DiClemente et al. 1985) and there is a shift from cons being perceived as being more important than pros in precontemplation, to pros being perceived as 
Table 2. The processes of change

\begin{tabular}{ll}
\hline Process & Definition and intervention strategies \\
\hline $\begin{array}{l}\text { Experiential: } \\
\text { Consciousness raising (CR) }\end{array}$ & $\begin{array}{l}\text { Increasing understanding and awareness of self and problem } \\
\text { behaviour (observations, bibliotherapy) } \\
\text { Experiencing and expressing strong emotional reaction to events } \\
\text { occurring in the environment; involves catharsis (psychodrama, } \\
\text { role-playing) } \\
\text { Appraising the pros and cons associated with changing the problem } \\
\text { behaviour (clarify values, imagery, imagine how overcoming problem } \\
\text { will feel) }\end{array}$ \\
Appraising how one's problem behaviour affects other people or the \\
environment in general (empathy training) \\
Environmental re-evaluation (ER) & $\begin{array}{l}\text { Is concerned with changes in the environment that provide the } \\
\text { individual with alternatives (policy intervention) }\end{array}$ \\
Social liberation (SL) & $\begin{array}{l}\text { Choosing and committing to act, believing in ability to change } \\
\text { (decision-making therapy) }\end{array}$ \\
Behavioural: & $\begin{array}{l}\text { Substituting alternatives for problem behaviour (relaxation, } \\
\text { desensitization, assertion) } \\
\text { Removal of cues or avoidance of situations which trigger the } \\
\text { behaviour, restructuring one's environment to add stimuli for } \\
\text { alternative behaviours }\end{array}$ \\
Counter-conditioning (CC) & $\begin{array}{l}\text { Trusting others, and accepting and utilizing their support to change } \\
\text { (social support, self-help groups) } \\
\text { Rewarding oneself or being rewarded by others for making changes } \\
\text { (contracts, overt and covert reinforcements) }\end{array}$ \\
Helping relationships (HR) &
\end{tabular}

more important than cons in the later stages. The latter observation has been replicated across many behaviours (Prochaska et al. 1994).

Change strategies. The ten processes of change form the basis for intervention (Table 2). They are the common strategies or techniques, emerging from a comparative analysis of various psychotherapeutic approaches (Prochaska, 1979) that can be used to change behaviour. For example, 'consciousness raising', from the Freudian tradition, involves gaining an awareness or understanding of the problem, and 'reinforcement management', from the Skinnerian tradition, involves increasing the rewards for the healthy behaviour, and reducing the rewards for the unhealthy behaviour. Other processes involve self-reappraisal, supportive relationships, and commitment. Research across a number of behaviours (including smoking, weight control, psychological distress, exercise, alcohol abuse) demonstrates that precontemplators infrequently use all processes, that use of those processes which involve gaining insight and understanding (experiential processes, or emotional or cognitive strategies) increases in contemplation and peaks in the preparation stage, while those in action and maintenance are more likely to use behavioural processes (Prochaska \& DiClemente, 1985; Prochaska et al. 1988; Rossi et al. $1991 b$; Rossi, 1992b). Successful change appears to depend on doing the right things (processes) at the right times (stages). Although the oldest part of the model, the processes of change are the least studied aspect outside the smoking cessation research.

\section{How do we test whether the transtheoretical model is valid for dietary change?}

Before reviewing the available data on applications of the model to eating behaviour change, let us examine the types of data required to test the hypothesis that dietary change follows a stage 
process. Weinstein et al. (1998) provide a more detailed account of suitable research designs for testing stage theories generally.

\section{Cross-sectional studies}

Initial steps taken to study the TTM as applied to eating behaviour involve comparison of people classified in different stages in terms of variables presumed to differ across the stages. At the simplest level are comparisons of eating behaviour and demographic characteristics. Comparisons of differences in process use, self-efficacy and decisional balance across the stages provide tests of model predictions. While smooth, linear changes across stages are consistent with the stages representing an underlying continuum, changes across stages which show different patterns for different variables and are of different magnitudes, suggest (but do not provide conclusive support for) a stage model (Weinstein et al. 1998).

Perhaps the strongest cross-sectional test of the model is whether different variables are important in predicting membership of specific stages relative to other stages. In other words, are different variables important in discriminating precontemplators from those in later stages, than are important in discriminating those in preparation from those in action or maintenance?

\section{Longitudinal studies}

Longitudinal studies can provide a variety of more powerful tests of the model, examples being: testing the hypothesized sequence of stages, whether stage classification predicts future behaviour, and whether different factors predict different stage transitions.

Such tests using longitudinal data have rarely been undertaken for eating behaviour change. Thus it is useful to outline briefly the types of longitudinal data supporting the contention that smoking cessation follows a stage process, since these provide some ideas of the kinds of analysis which might usefully be applied in studies of eating behaviour change.

Prochaska et al. (1991) demonstrated using 6-monthly stage classifications over a 2-year period that, although $36 \%$ of smokers and ex-smokers stayed in the same stage for all of the five examination points, $16 \%$ progressed from one stage to the next in the specified sequence without any regression. Stage classification for smoking cessation also predicts future behaviour: smokers in the preparation stage are three times as likely to quit smoking over 18 months as those in the precontemplation stage (Prochaska et al. 1992a). Prochaska et al. (1985) also observed that self-efficacy contributed strongly both to the transition from contemplation to action and from action to maintenance, but that decisional balance predicted change for those in the precontemplation and contemplation stages. Intuitively, it makes sense that for those in the early stages not yet committed to the idea of change, the most important predictor of progression to later stages is the relative importance of the pros and cons of changing, but that confidence in ability to perform the new behaviour is the more important factor later on once a decision or commitment to change has already been made. Another longitudinal analysis (Prochaska et al. 1992a) has shown that people who remain at the same stage for prolonged periods show little change in the use of processes, while those progressing from one stage to the next demonstrate a gradual increase in the overall process use. The utility of self-efficacy has also been shown in a longitudinal study of volunteers trying to quit smoking. Lower selfefficacy scores were predictive of subjects who remained in the same stage or relapsed (DiClemente et al. 1985). 
The ultimate test: stage-matched interventions

The ultimate test of the model is whether stage-matched dietary interventions outperform standardized approaches. According to the model, if different factors influence transitions at different stages, then individuals should respond better to interventions tailored to match their stage of change.

For smoking, individualized self-help materials matched to stage and other TTM variables more than doubled the rate of cessation compared with traditional, action-oriented self-help manuals (Prochaska et al. 1993).

Weinstein et al. (1998) have gone a step further in noting that only stage models predict that the sequence of interventions is important in determining intervention efficacy. Stageappropriate interventions sequenced to follow the sequence of hypothesized stages should be most effective; however no one has yet investigated the effects of using different sequences of treatments.

\section{An overview of findings from the reviewed literature in Table 1}

Table 1 summarizes studies which have applied the TTM to eating behaviours, dividing them into broad categories according to the approach used to test the model. All studies identified since 1988 covering all age groups are included in the table. Over one-third were published in 1998 or will appear in 1999, and a number of unpublished manuscripts from Prochaska's group are included. About two-thirds of studies were concerned with the goal of lowering dietary fat intakes. Studies have been undertaken among predominantly Caucasian populations, with only one specifically exploring model constructs in African-Americans (Campbell et al. 1998) and one in Chinese-Singaporeans (Ling \& Horwath, 1999a,b; A Ling and CC Horwath, unpublished results).

Studies in group 1 (Table 1) involve cross-sectional comparisons mainly of eating behaviour and demographic characteristics across the stages of change. Group 2 studies test modelpredictions using cross-sectional data by examining changes across the stages, and are further divided into two categories: 2(A) includes comprehensive tests of all aspects of the model, while 2(B) examines only selected constructs from the TTM or other theories and models. Group 3 includes longitudinal studies which provide the opportunity to examine whether stage classification is related to the probability of successful behaviour change in the future. Group 4 studies provide the ultimate test of the model by examining the effectiveness of stage-matched interventions relative to standardized approaches.

The 'dietary assessment' column (Table 1) indicates the reference method chosen to evaluate whether those classified in different stages differed in their eating habits in the predicted manner. This is the common approach taken to 'validating' the stage classification system. The 'stage distribution' column shows the sample distributions by stage (reported in some studies separately by sex or different dietary goals) and also indicates whether any brief objective measure of intake was included as an integral part of assessing stage (discussed in detail later, pp. 299-302). In assessing stage, 'subjective' measures of eating behaviour are considered to be those based on subjects' self-perceptions of, for example, whether they are eating a low-fat diet or limiting fat intake (e.g. Curry et al. 1992). In contrast, 'objective' measures of eating behaviour are considered to be those undertaken by the researchers, usually using a short questionnaire or interview (e.g. Sorenson et al. 1998; Ling \& Horwath, 1999b).

As Table 1 clearly shows, most dietary applications of the model involve cross-sectional studies, and many examine only the stage construct. A number of these simply compare dietary 
intake at different stages, while others examine whether those classified in different stages differ in socio-demographic characteristics or various attitudes or beliefs (de Graaf et al. 1997). However, it cannot be emphasized strongly enough that mere demonstration of dietary intake or socio-demographic differences across the stages does not demonstrate, as has often been assumed, that eating behaviour change follows a stage process.

About one-third of studies examined to some degree the associations between other aspects of the TTM and the stage variable (e.g. Bowen et al. 1994; Lamb \& Joshi, 1996; Steptoe et al. 1996; Ling \& Horwath, 1999a; A Ling and CC Horwath, unpublished results), and only three groups of investigators included measurement of all the TTM constructs (Prochaska et al. 1992a; Rossi et al. 1994c,d; Ounpuu, 1997, 1999b; Gulliver, 1998; Horwath \& Gulliver, 1998). These latter studies are capable of providing the most comprehensive test of model predictions. Other investigators have compared people at different stages using variables derived from other behavioural theories (Sporny \& Contento, 1995; Glanz et al. 1998a). Only five studies reported predictions of stage membership (Sporny \& Contento, 1995; Ling, 1999) or whether stage predicts future behaviour (Beresford et al. 1997; Glanz et al. 1998b; Jeffery et al. 1999) and only one tested the effectiveness of a stage-matched intervention (Campbell et al. 1994).

While there is much convincing evidence from studies at all levels that smoking cessation follows a stage process, as will be discussed later (pp. 304-308), the validity of the TTM and effectiveness of stage-matched interventions have been less thoroughly tested for eating behaviour change.

Since Table 1 provides considerable detail on study design, sample characteristics, methods and key findings, the following discussion will highlight important issues arising in applications to eating behaviour change, summarize the main conclusions that can be drawn from the reviewed literature, as well as raise unanswered questions. Direct study comparisons are made difficult by substantial differences in study populations, methods used to assess stage, and dietary methodology. Although included in Table 1, weight-control applications will be discussed separately in a later section (pp. 308-309), since this goal includes a complex set of behaviours (eating habits, exercise, use of medications or other substances to control weight).

\section{Methodological challenges in applying the model to eating behaviour change}

The immediate dilemma which faces anyone attempting to apply the model to eating behaviour is a realization of the numerous ways in which dietary change differs from smoking cessation (Table 3). Dietary guidelines involve themes of balance and moderation, with goal behaviours (or action criteria) being gradations of intake, often achieved as a result of multiple changes to

Table 3. Differences between eating behaviour change and smoking cessation

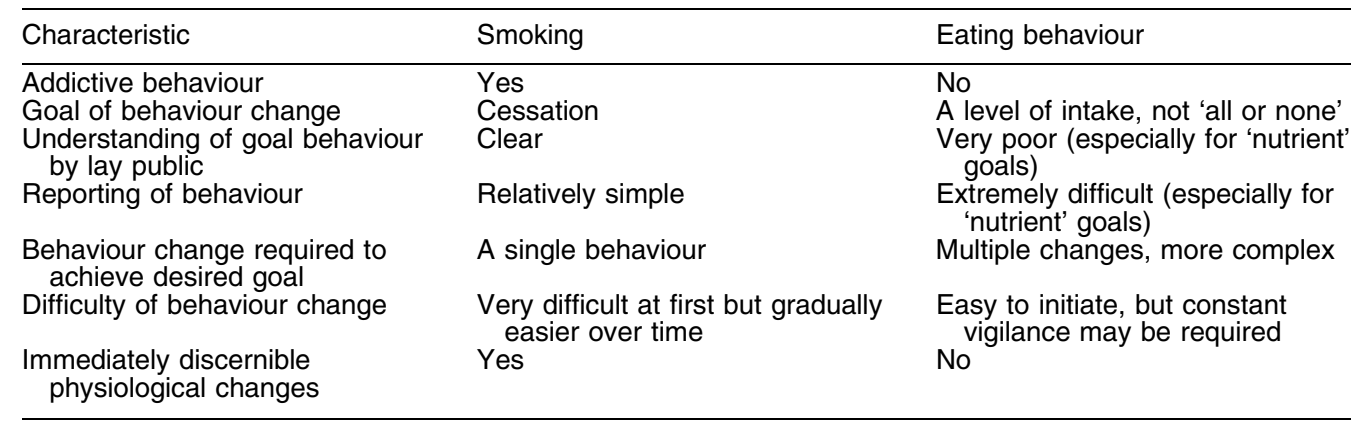


food selection patterns, preparation methods or serving sizes consumed. Nutritionists obviously do not wish anyone to cease eating, or even to cease eating a particular food group or nutrient such as fat! Dietary behaviours are usually complex behaviours which are difficult to report, since most people lack the knowledge to rate their own diets in terms of say, fat or fibre (Greene et al. 1993). Essentially, the problem is that for dietary goals, people do not know where they are at in relationship to the action criterion, or what changes they would need to make in order to reach the criterion. While smoking cessation becomes easier with time, it may be that with eating behaviour change, constant vigilance is required to make many healthy choices over unhealthy options over an extended period of time (Jeffery et al. 1999). Perhaps for eating behaviour change, the risk of relapse remains high since people are constantly confronted with social situations in which a range of less healthy choices are available and modelled by others. Some evidence suggests social situations to be a far more common reason given for relapse by those attempting eating behaviour change than by those quitting smoking (Marlatt, 1982). Furthermore, there is a multitude of different eating styles and individual food preferences that could be compatible with the ultimate goal of eating, for example, a low-fat diet. It can also be questioned whether the factors responsible for transitions between adjacent stages are the same for changing eating behaviour as for smoking cessation.

\section{Stage classification for readiness to change eating behaviour}

A staging algorithm, or series of mutually exclusive branching questions, is the most common method for assigning stage classifications (e.g. Prochaska et al. 1992; Sorenson et al. 1998). The alternative continuous-scales approach (in which there is a series of statements designed to capture the essence of each stage) assigns each individual a score on each stage (Prochaska et al. $1992 a, b)$. The latter approach is not intended to be used to assign individuals to discrete stages of change. Rather, the continuous method can indicate stage profiles for individual subjects and identify those with variations or complex combinations of stage-specific attitudes and behaviours (McConnaughy, 1989), or subtypes of individuals within a stage (Rossi et al. 1995b).

Several issues must be addressed regarding stage classification approaches for dietary behaviour changes. These are vital for effective use of the model not only by TTM researchers, but also practitioners. Currently there is no clear consensus on stage definitions for eating behaviours.

Obviously stage distributions are strongly influenced by the classification system. If dietary behaviour goals (or action criteria) are poorly understood, errors occur not only in the assignment of stage, but with all TTM constructs, since items to measure all constructs include reference to the goal behaviour. Most importantly, correct stage classification is essential for the delivery of stage-matched interventions.

\section{Should stage assessment include an objective behavioural measure?}

One key issue which has arisen with dietary applications of the model is whether stage classification should be based on entirely subjective assessments (i.e. do people perceive themselves to be eating a low-fat diet) or more objective assessments of behaviour (i.e. a short dietary assessment undertaken by the researchers). Of course, all dietary assessments based on selfreporting are to some extent subjective. The question is whether 'stage' is a purely cognitive construct, or involves a behavioural element. Most dietary applications of the model have involved subjective assessments by subjects of whether, for example, they are 'limiting the fat 
in their diet', 'consistently avoiding high-fat foods' or 'eating a low-fat diet' (Curry et al. 1992; Glanz et al. 1994; Greene et al. 1994; Sporny \& Contento, 1995; Steptoe et al. 1996). However, many of the large proportion of subjects classified in action or maintenance in these studies consumed a diet with more than $30 \%$ of energy from fat (Glanz et al. 1994; Greene et al. 1994; Sporny \& Contento, 1995; Brug et al. 1996; Steptoe et al. 1996; Ounpuu, 1999a) and have been referred to as pseudomaintainers (Greene et al. 1994). This problem arises largely from those issues outlined in Table 3 concerning the nature and specification of the goal behaviour. But Prochaska et al. (1997) maintain that in order to be classified in action, people must attain the criterion that health professionals have agreed upon for reduction of disease risk (i.e. if lowering fat intake is chosen as the goal: less than $30 \%$ energy as fat) (Rossi et al. 1995b; Prochaska et al. 1997).

The misclassification of most subjects into action and maintenance stages, despite $75 \%$ of these subjects having fat intakes above $30 \%$ of energy, led Greene et al. (1994) to develop an approach whereby the subjective algorithm was followed by an objective assessment of five specific fat-reduction behaviours. Subjects who on the basis of the subjective algorithm were classified in action or maintenance, but who failed to meet at least four of the five objective criteria, were reclassified into the preparation stage. While this approach is successful in classifying the majority ( $87 \%$ ) of those with fat intakes above $30 \%$ of energy into preaction stages, a minority $(27 \%)$ of those with fat intakes below $30 \%$ of energy were classified in action or maintenance. It might be argued that for screening purposes, it is less problematic to reinforce fat-reducing messages in those already meeting the guideline than it is for those not meeting recommend-ations to lose the possibility of an intervention; however, clearly this classification approach cannot be used as the basis for personalized feedback on how people are changing. Furthermore, the question remains as to the appropriateness of staging on the basis of poorly understood questions, and then of reclassifying, using more objective criteria, only a subgroup of subjects into an arbitrarily chosen stage. In fact, pseudomaintainers have been found to be a heterogeneous group composed of individuals at all earlier stages (Rossi \& Rossi, 1993).

Ounpuu (1999a) has explored the characteristics of pseudomaintainers and found they were similar to true maintainers in terms of self-efficacy level, but that true maintainers reported lower cons for fat reduction and higher use of all nine processes of change. Although pseudomaintainers were more similar in terms of actual behaviour to precontemplators, pseudoand true maintainers appeared more similar to each other than to precontemplators when other TTM variables were examined. The similar self-efficacy levels are not surprising, simply suggesting that both pseudo- and true maintainers were confident of maintaining their current perceived low level of fat intake. Have pseudomaintainers already markedly reduced fat intake from extremely high levels to intakes which are still as high as those of precontemplators (38\% energy)? Or is it simply that they are particularly unaware of the characteristics of a low-fat diet and unaware of their own eating habits? Pseudomaintainers comprised $>25 \%$ of the total population staged in this study and a similar or higher (Greene et al. 1994) proportion in other studies. What remains unclear is how this sizeable group should be handled in the stage classification process. The investigators (Ounpuu et al. 1999a) concluded that the results suggest the need for individual tailoring within stage of change. Perhaps this implies that TTM variables other than stage are more meaningful in applications to dietary fat reduction?

Further attention must also be paid to the validity of the objective component of any staging classification system. The behavioural algorithm used by Greene et al. (1994) incorporated fat reduction behaviours selected from the questionnaire of Kristal et al. (1990). Evaluation of the Kristal fat-screening instrument, however, indicates that it is not a sensitive method of identifying high or low fat consumers (Birkett \& Boulet, 1995). Use of questions 
from such a screener would undoubtedly lead to misclassifications in stage assignment. The same fat screener has also frequently been used as the reference dietary assessment measure (Curry et al. 1992; Rossi et al. 1994c; Sporny \& Contento, 1995; Auld et al. 1998): that is, as one test of the validity of the staging algorithm. Yet if the reference method is not a sensitive measure of intake, how useful is such a comparison?

More recently, Greene \& Rossi (1998) have proposed a new approach to classifying 'true maintainers' that combines subjective and objective assessments: self-report of fat avoidance for more than 6 months, plus two estimations 6 months apart of assessed fat intake below $30 \%$ of energy intake. Only $19 \%$ of 'true maintainers' relapsed, in contrast to $31 \%$ of self-classified maintainers. Such an approach precludes, however, the possibility of rapid stage assessment for large population groups.

Other objective assessments of behaviour as an integral part of staging instruments are rare. During brief phone interviews, CC Horwath and P Gulliver (unpublished results) estimated typical daily servings of milk products before questions focusing on intentions to change. The phone interviews enabled investigators to assist respondents in estimating their usual intake, then, before questions regarding intentions, to ensure they clearly understood both the nature of the goal behaviour and the discrepancy between their current behaviour and the foodbased goal. Ling \& Horwath (1999a,b) and A Ling and CC Horwath (unpublished results) used a short self-administered validated food frequency questionnaire to assess intake of fruit, vegetables and cereal foods, as an integral part of stage assessment. Estimates were checked in a subsequent phone interview, during which the goals were clearly described and questions concerning intentions asked. Sorenson et al. (1998) also used, as an integral part of determining stage, a seven-item fruit and vegetable screener.

Use of these objective assessments of behaviour appears to largely overcome the major misclassification problem found with subjective assessments of stage. In the studies of Horwath \& Gulliver (1998), CC Horwath and P Gulliver (unpublished results), Ling \& Horwath (1999a, $b$ ) and A Ling and CC Horwath (unpublished results), the mean intakes of those classified in action and maintenance did meet the behavioural goals, and furthermore Ling \& Horwath $(1999 b)$ found that the majority of individuals classified in these stages met the goals according to an independent dietary assessment measure (three $24 \mathrm{~h}$ recalls). Of course, it is not surprising that when a more objective behavioural component is an integral part of the algorithm, stage and intake are associated in this manner. The crucial point is that the problem of having a sizeable group of pseudomaintainers largely disappears with the use of more objectively measured, clearly understood food-based goals.

Auld et al. (1998) have taken a dramatically different approach to stage classification, using not only objective behavioural measures, but also questions regarding attitudes and beliefs related to the behavioural goals, the perceived importance of diet-disease links, and willingness to adopt specific dietary practices. The authors contend that attitudes must be added to behaviour and intention in the stage assessment process. However, they note that it was impossible to distinguish between subjects in action and maintenance. Furthermore, this approach made impossible an unambiguous stage classification for $35 \%$ of participants. If we accept the defining characteristics of stage theories put forward by Weinstein et al. (1998) (i.e. a stage theory requires a classification system for assigning each individual to only one stage), this classification method is untenable.

An alternative approach has been taken by Glanz et al. (1994, 1998a,b) who view stage status as 'cognitive and self-perceived rather than overtly behavioural'. Once again subjective stage assignment resulted in people being classified in action or maintenance for following a low-fat diet, despite mean fat intakes above the goal level, or for following a high-fibre diet 
despite mean fruit and vegetable servings of only half the recommended level. However, what is seen as important is whether people themselves consider that they are following, for example, a low-fat diet. A person classified in action may well fall above $30 \%$ energy as fat, but have adopted some fat-reducing behaviours (e.g. use of reduced-fat milk) and have significantly reduced their percentage energy from fat from a still higher level. Indeed, some evidence supports the contention that people who perceived themselves to have changed (i.e. reported a change in stage) actually did change their eating behaviour, as determined by independent measures of dietary intake (Glanz et al. 1998b). People thus appear aware of whether they are moving in the right direction with their dietary change, but are likely to consider that they have reached the targets of low-fat or high-fibre eating when they still have a considerable way to go (Brug et al. 1994). Although these considerations are undoubtedly valid given the complex nature of dietary change, the essence of a stage model is that people can be divided into those who are and those who are not currently performing the goal behaviour. It is certainly preferable to acknowledge small positive steps taken towards a goal and to encourage further efforts in new areas. However, this tailoring of messages to the particular fat-reducing behaviours that have or have not been achieved, could be undertaken simply on the basis of a dietary assessment without the use of any stage approach, something which has in fact been done (Brug et al. 1998a). The alternative assessment of stage in relation to each fat-reducing behaviour (e.g. a subject may be in maintenance for trimming fat from meat, but in contemplation for using skimmed milk) (Ni Mhurchu et al. 1997) would, for most purposes, be too complex and time-consuming. Using just such an approach, Birkett et al. (1993) have indeed confirmed that people tend to be at very different stages for individual fat-reducing behaviours.

Although the originators of this model clearly conceptualize stage as both cognitive and behavioural, and require those in action to be meeting action criteria rather than simply moving towards them, measurement methods consistent with this definition are problematic for low-fat or high-fibre eating. On the basis of currently available evidence, it appears likely that a stage model may be less appropriate for complex dietary changes such as low-fat eating, than for simpler more discrete behaviours such as eating five servings of fruit and vegetables per day, or drinking low-fat milk. Purely cognitive stage assessments of low-fat or high-fibre eating appear to have value as intermediate markers of dietary change (Glanz et al. 1998a,b). Other behavioural models may prove easier to apply to complex goals such as dietary fat reduction (Stafleu et al. 1991/2).

\section{Defining dietary goals and stages}

An important consideration arising when attempting to determine stage of readiness to change eating behaviour is whether the goal is stated simply as the direction of the desired shift (i.e. 'do you intend to eat more fruit/vegetables?', 'have you limited the fat in your diet?') or as a specified level of intake (i.e. 'do you intend to eat five servings of fruit and vegetables per day?'). While a small number of investigators have taken the latter approach (Laforge et al. 1994; Horwath \& Gulliver, 1998; Ling \& Horwath, 1999a,b; A Ling and CC Horwath, unpublished results; CC Horwath and P Gulliver, unpublished results), most have not specified the ultimate goal behaviour (Table 1; e.g. Brug et al. 1997; de Graaf et al. 1997; Campbell et al. 1998; Sorenson et al. 1998). The eating behaviour of those classified in action and maintenance will vary widely when only the direction of change is specified. As expected, a far higher proportion of people reported preparing to 'eat more fruit and vegetables' (Campbell et al. 1998) than were preparing to eat five or more servings per day (Laforge et al. 1994). Laforge's algorithm also included a behavioural criterion to define preparation (3-4 servings per day). 
Similarly, the proportion in maintenance is higher if people are asked about 'limiting the fat in their diet' as opposed to 'being on a low-fat diet' (Rossi et al. 1993a).

As previously mentioned, there is no real basis for the use of particular time frames in defining stages for eating behaviour. However, in the absence of evidence for other time frames, it would seem reasonable to test the TTM initially using the same time frames as have been found useful for smoking cessation (Sorenson et al. 1998). Use of exactly the same time frames and intentional criteria (Rossi et al. 1994a,b,c; Ounpuu, 1997; Horwath \& Gulliver, 1998; Ling \& Horwath, 1999a,b) as for smoking cessation, has led to the demonstration that process use, self-efficacy and decisional balance change across the stages in just the manner predicted by the TTM. This provides some support for the usefulness of these time frames; however, further longitudinal analyses using such classification systems are required.

Various modifications of the original stage definitions have been employed in other studies. For example, several investigators (Curry et al. 1992; Steptoe et al. 1996) defined people in precontemplation, contemplation or preparation as those who were not currently limiting the amount of fat in their diet or had never changed their eating habits to decrease the amount of fat in their diet but had (contemplation and preparation only) thought during the past month about changes they could make. A few dietary staging algorithms have included a behavioural criterion to define preparation (Laforge et al. 1994; Horwath \& Gulliver, 1998; Ling \& Horwath, 1999a,b; A Ling and CC Horwath, unpublished results; CC Horwath and P Gulliver, unpublished results). In the studies of Steptoe et al. (1996) and Curry et al. (1992), contemplators and those in preparation were distinguished on the grounds of their degree of confidence that they would make some changes during the next month, that is, using a separate construct of the model. Campbell et al. (1999) have also highlighted the effects of small differences in wording (e.g. planning to $v$. decided to) on stage classification. In the absence of consistency in staging algorithms for dietary change, cross-study comparisons are impossible.

Since children do not have well-developed methods of time estimation, the only application of the model to children has involved multi-item scales to assess stage (Domel et al. 1996). The findings led the investigators to question whether the stage concept itself has any relevance to children. Only two factors (precontemplation and beyond precontemplation) were identified, and no differences were found by stage in either fruit and vegetable consumption or preferences. However, it would be premature to dismiss the model as inapplicable to children on the basis of one study. Many of the items appear nonsensical (e.g. 'I am working on eating more fruit and vegetables to learn about myself'), vague (e.g. 'After all I have done to try and eat more fruit and vegetables, every now and then it still worries me': what is 'it'?) or involve more than one concept which creates difficulty in answering (e.g. 'I have worries about what I eat, but so do other children. Why spend time thinking about them?': does 'them' refer to the worries or the other children?).

In measuring other aspects of the TTM with a view to examining patterns of change across stages, questions should match the goal behaviour referred to in the staging algorithm. This has not always been the case. For example, individuals staged for the goal of dietary fat reduction were asked to respond to decisional balance items concerning 'eating healthy food' (Steptoe et al. 1996).

\section{Recommendations for assigning stages}

It would appear that the following factors are likely to improve the accuracy of stage classification for dietary change: more clearly specified and easily understood behavioural goals, and 
the inclusion of an objective component in the assessment of current behaviour. Ideally this objective measure should have been previously validated as a measure of intake in the population of interest and the resulting stage classification needs to be validated by comparison with an independent assessment of dietary intake. Clearly, food-based goals are more readily understood than nutrient goals. Explanation of what constitutes a serving of a particular food group is considerably easier than describing, for example, a 'low-fat diet'. Furthermore, the sensitivity, specificity and predictive values for algorithms to assess food-based goals (Ling \& Horwath, 1999b) are comparable to or better than those for dietary fat reduction (Greene et al. 1994; Auld et al. 1998). A classification scheme must be able to classify unambiguously each individual into one stage, and must be consistent with the fundamental ideas of the TTM which emphasize the tendency for relapse and recycling through the stages.

\section{Stage distributions for eating behaviours}

The skewed distributions toward action and maintenance for dietary fat reduction are an artifact arising from the difficulty of subjectively assessing stage for 'nutrient' goals. For fruit and vegetable goals, however, stage distributions are more consistent with what is known about population dietary habits, but encouragingly there appears to be a high degree of interest in starting to eat more fruit and vegetables (Campbell et al. 1998; Ling \& Horwath, 1999a,b; A Ling and CC Horwath, unpublished results).

From a small number of studies assessing stage for more than one dietary behaviour, it is clear that agreement between stage of change for different goals is poor (Glanz et al. 1998a; Ling, 1999). That is, success in meeting one behavioural goal does not necessarily imply motivation to make other dietary changes. A similar lack of agreement in stage classification also occurs across diverse health behaviours (Herrick et al. 1997).

Despite variations in classification systems, sex differences are generally consistent in terms of women being more ready to reduce fat intake, increase fruit and vegetable consumption (Curry et al. 1992; Lamb \& Joshi, 1996; Steptoe et al. 1996; Auld et al. 1998; Campbell et al. 1998; Ling \& Horwath, 1999b) or try 'healthier eating' (de Graaf et al. 1997), but men being more ready to follow cereal-product consumption goals (Ling, 1999; Ling \& Horwath, 1999b).

\section{Processes}

Despite being the oldest part of the TTM, this is the least studied aspect in applications to eating behaviour change. This may be due to poor understanding of the processes themselves and the difficulty of developing valid questionnaires to measure them. Questions to assess processes measure how often the thoughts, events or activities described in the various change strategies are used or experienced (Ounpuu, 1997). Others have used questions that tap attitudes or beliefs about fat reduction and nutrition knowledge and which appear to have low content validity in relation to the original conceptualization of processes (Lamb \& Joshi, 1996). For example, 'To reduce the fat in my diet in the next month would be difficult' does not assess process use (Lamb \& Joshi, 1996). In developing process questionnaires, it is particularly important not only that items are carefully tested in focus groups, but also that expert judges well versed in the TTM are used to establish item content validity (Rossi \& Rossi, 1993).

Aside from the research of Prochaska's group (Rossi \& Rossi, 1993; Rossi et al. 1994b,d), investigations of the processes of change are rare (Bowen et al. 1994; Ounpuu, 1997; Horwath 
\& Gulliver, 1998). CC Horwath and P Gulliver, unpublished results). Some researchers have only developed questions to assess four processes, and did not employ factor analytic techniques (Lamb \& Joshi, 1996). Such an approach does not permit any conclusions to be drawn concerning whether the same or fewer processes operate in dietary fat reduction as in quitting smoking.

In general, the small number of studies on dietary fat reduction and milk-product consumption (Table 1) confirm the existence of between eight and eleven processes for dietary change, the two broader groupings of experiential and behavioural processes, the increasing use of processes across the stages, and significantly different levels of use of various processes at different stages. Stimulus control appears to be the process used most often for dietary change (Prochaska \& DiClemente, 1985; Horwath \& Gulliver, 1998; CC Horwath and P Gulliver, unpublished results).

The difficulty in developing discrete scales with a high degree of internal consistency to measure counterconditioning and stimulus control has been a consistent finding across different dietary behaviours (Rossi \& Rossi, 1993; Bowen et al. 1994; Gulliver, 1998; Horwath \& Gulliver, 1998). Clearly more work is needed to refine questionnaires to measure these processes. The existence of discrete reinforcement management and self-liberation processes has also been difficult to validate for eating behaviours (Bowen et al. 1994; Gulliver, 1998; Horwath \& Gulliver, 1998). However, it is plausible that a different set of processes may operate for eating behaviour change than for quitting smoking, and that different processes may be valid for different dietary changes.

Given the different nature of eating behaviour change as compared with smoking cessation, one key difference observed in patterns of process use is not surprising. Whereas in smoking cessation the overall use of processes begins to decline once in maintenance (Prochaska \& DiClemente, 1983), use of dietary change processes continues at high levels in the maintenance stage (Rossi \& Rossi, 1993; Bowen et al. 1994; Ounpuu, 1997; Gulliver, 1998; Horwath \& Gulliver, 1998; P Gulliver and CC Horwath, unpublished results). This confirms the hypothesis that eating behaviour change requires constant vigilance, and may preclude the possibility of reaching a point where no effort is required. The acquisition of exercise appears to be similar (Marcus et al. 1992).

In one of the few investigations of the processes of eating behaviour change, findings were exactly as predicted by the TTM: infrequent utilization of all processes by precontemplators, more frequent use of experiential processes in contemplation and preparation, and greater use of behavioural processes in action and maintenance (Gulliver, 1998; Horwath \& Gulliver, 1998; P Gulliver and CC Horwath, unpublished results). Careful attention had been paid to item pretesting in focus groups, as well as inter-rater reliability assessments in which items were retained only if all three judges expert in use of the TTM agreed on the process being measured.

\section{Self-efficacy}

The self-efficacy construct appears promising as a means of monitoring and predicting stage transitions for dietary change. In cross-sectional studies, self-efficacy has been associated with stage of change for dietary fat reduction (Rossi, 1993; Rossi et al. 1994a; Sporny \& Contento, 1995; Ounpuu et al. 1999b), milk-product consumption (Horwath \& Gulliver, 1998; CC Horwath and P Gulliver, unpublished results), fruit and vegetable consumption (Campbell et al. 1999; Ling \& Horwath, 1999a) and cereal-product consumption (Ling, 1999). Scores were significantly higher in action and maintenance than in the earlier stages. Sporny \& Contento (1995) found that self-efficacy dipped in contemplation, but increased in action and then even 
further in maintenance. In this latter study, however, maintenance was defined as following the goal behaviour for at least 2 years rather than 6 months and this may contribute to the even higher self-efficacy levels found in maintenance than in action.

There is also some evidence for the multidimensional nature of self-efficacy for eating behaviour change (Rossi et al. 1994a; Ling \& Horwath, 1999a; Ounpuu et al. 1999b), as for smoking (Velicer et al. 1990). Other studies, however, have only included one or two item measures of self-efficacy (e.g. Brug et al. 1996, 1997; Campbell et al. 1998, 1999).

\section{Decisional balance}

Across studies of a variety of dietary changes, which include dietary fat reduction (Rossi et al. 1994c; Steptoe et al. 1996; Ounpuu, 1997), and increased consumption of milk products (Horwath \& Gulliver, 1998; CC Horwath and P Gulliver, unpublished results), fruit and vegetables (A Ling and CC Horwath, unpublished results) and grains (Ling, 1999), the two factor structure (i.e. pros and cons) for decisional balance was remarkably stable (Prochaska $e t$ al. 1994). Across all the dietary changes studied, the following consistent pattern emerged: cons higher than pros in precontemplation; pros increase between precontemplation and contemplation; cons lower in action than in contemplation; and usually the pros were higher than the cons in action.

Instead of remaining stable between precontemplation and contemplation as found in most studies of other health behaviours (Prochaska et al. 1994), in studies of dietary fat reduction (Rossi et al. 1994c) and weight control (O'Connell \& Velicer, 1988), the cons have been found to increase in contemplation along with the pros. This suggests that when grappling with the decision to change eating habits, considerations of both negative aspects and incentives for change are important.

Sporny \& Contento (1995), using health belief model concepts, found that perceived benefits increased across the stages, but that perceived barriers peaked in contemplation then declined in the later stages. The lower perceived barriers and higher self-efficacy of precontemplators compared with contemplators in this study, may be the result of unrealistic expectations. Also drawing on other theories of health behaviour, Glanz et al. (1994) found a link between stage of change and both self-efficacy and motivation to lower fat intake.

\section{Are different factors important in producing transitions at different stages?}

Only a minority of studies have attempted to address this important defining characteristic of stage models. The cross-sectional nature of the studies means they provide information on whether different factors distinguish those in different stages, but cannot provide conclusive evidence of the importance of different factors in producing different stage transitions.

For dietary guidelines concerning fruit and vegetables and cereal products, Ling (1999) recently tested TTM predictions and found that decisional balance was most important in distinguishing precontemplators from people in the other stages, while self-efficacy was more important in determining whether people were actually meeting dietary goals as oppposed to contemplating or preparing for change. Not only does this make sense (i.e. if one has no interest in changing, confidence in ability to make changes would appear far less relevant than a shift in the way one sees the relative pros and cons of changing; however, once one is fully committed to change, decision-making issues would seem likely to be less important than skills), it is also consistent with longitudinal investigations of self-changers' smoking status (Prochaska et al. 1985). 
Using variables from a number of behavioural theories, Sporny \& Contento (1995) in an application to dietary fat reduction, demonstrated that the factors which most strongly differentiated contemplators from precontemplators were motivational beliefs from the health belief model (including perceived benefits and susceptibility, cues to action), motivation to comply and self-efficacy (negative direction). The variables most strongly differentiating those in action from contemplators were perceived benefits and barriers, health concern, motivation to comply, social modelling and self-efficacy. Those in maintenance were most strongly discriminated from those in action by perceived susceptibility and perceived barriers (negative direction), health concern, social modelling and self-efficacy (positive direction). The finding of Sporny \& Contento (1995) that perceived barriers are most important in distinguishing those in the later stages, while perceived benefits are most important in distinguishing those in the earlier stages differs from the work of Ling (1999) and Prochaska et al. (1985).

\section{Longitudinal studies}

Most of the longitudinal data available comes from intervention studies (not stage-matched) which included an assessment of stage as an indicator of change. From these studies, it appears that baseline stage predicts degree of dietary change (Beresford et al. 1997; Greene \& Rossi, 1998) and participation in health behaviour change strategies (these appeal most to people who are classified as having greater levels of readiness to change) (Glanz et al. 1998b) and that movement to later stages was both linked with desirable dietary shifts and was more likely in intervention groups (Glanz et al. 1998b).

\section{Intervention studies}

Campbell et al. (1994) compared the effects of a single personalized, staged-matched intervention and a non-tailored intervention. Using a computer software package, tailored interventions were created from subjects' responses to brief measures of stage of change, current dietary intake, motives, barriers, beliefs and self-efficacy for three dietary goals: eating less fat and more fruit and vegetables. The staging algorithms were based on the questions of Prochaska \& DiClemente (1983). The non-tailored intervention provided standard risk information about diet and disease and the dietary guidelines. Change was assessed at 4 months postintervention by a food frequency questionnaire. Total fat intake $(\mathrm{g} / \mathrm{d})$ decreased in the tailored group by $10.3(23 \%)$ compared with $3.6(9 \%)$ in the non-tailored group and $1.3(3 \%)$ in the control group. Differences were statistically significant only between tailored and control groups, but not between non-tailored and control groups.

The results are impressive, especially given that only a single mailout of materials was used. The study did not, however, examine the effect of the intervention on stage transitions, or whether baseline stage predicted behaviour change. Most importantly, the study cannot distinguish whether the greater effectiveness of the tailored message was due to its individualized feedback on current eating behaviour and psychosocial variables such as beliefs about susceptibility and motives for change, or whether matching to stage of change was crucial. Others have shown single, individualized dietary-feedback reports to accelerate the rate of fat reduction at 12 months, but to have no long-term effect (Greene \& Rossi, 1998).

Tailored interventions are not the exclusive domain of the TTM, or other stage models. A number of studies have evaluated the impact of individual computer-tailored nutrition interventions, including iterative feedback, on dietary intake (Brug et al. 1996, 1998a,b; Kreuter \& 
Strecher, 1996). In one study, feedback letters were tailored to dietary intake, intentions, attitudes, self-efficacy expectations and self-rated behaviour (Brug et al. 1998a). Such tailoring achieves some of the characteristics of interpersonal counselling, since much individual information is gathered in order to develop individual dietary advice relevant to a person's eating habits and associated beliefs.

All studies confirmed tailored approaches to be significantly more effective than general nutrition information; however, one study evaluated only the impact on self-reported fat reduction (Kreuter \& Strecher, 1996) and another assessed only short-term impact (3 weeks; Brug et al. 1996). Another study demonstrating the greater effectiveness of a tailored approach in achieving fat reduction and increased fruit and vegetable intake used a thirty-two item food frequency questionnaire to assess intake (Brug et al. 1998a). However, all participants in this study were volunteers who had responded to advertisements for free nutrition information, resulting in a study population that was largely female (82\%) and highly educated (42\% had a college degree). The population was thus likely to consist of those most ready to take (or at least consider) action (a common criticism of traditional nutrition education efforts). Precontemplators would not respond to such an advertisement. Whether this approach can be replicated in more representative samples would be of enormous interest.

\section{Applications to weight control or diabetes management}

The applicability of the TTM to outcomes such as weight control and diabetes control has been explored. However, it must be emphasized that these goals are not behaviours but outcomes influenced not only by a range of dietary behaviours, but by other complex behaviours as well (e.g. physical activity, use of medications and other substances, blood glucose monitoring, insulin administration). Thus attempts to apply the TTM in these situations may be even more problematic than application to the goal of dietary fat reduction.

In applications to weight control, stage classification has been made on the basis of statements about current weight and intentions to lose weight (O'Connell \& Velicer, 1988), or about current dieting or intentions to diet (Jeffery et al. 1999). Decisional balance items have referred mostly to individuals' perceptions of the consequences of losing weight (O'Connell \& Velicer, 1988), but some process items have referred specifically to overeating or binge eating (Rossi et al. 1994d). It is probably easier, however, for people to appreciate the benefits of actual behaviours such as regular exercise, than to focus only on the pros of losing weight.

Given the difficulty of weight reduction and the numerous contributing factors, it is hardly surprising that a few simple questions regarding whether a woman is currently dieting or intending to diet were of no use in predicting future weight change in the only large prospective study available (Jeffery et al. 1999).

Among thirty participants who completed measures at weeks one, five and ten of a 10week worksite weight control programme, it was found that significant shifts from contemplation to action occurred for those remaining in treatment, that use of several processes increased during the treatment programme and that those who moved from contemplation to action for attempting weight loss reported increased levels of self-efficacy (Prochaska $e t$ al. $1992 b$ ). Change processes used during the early portion of treatment were the best predictors of treatment attendance and amount of weight lost during treatment. However, study limitations include the small and non-representative sample, short study period, and use of a goal which is an outcome rather than a behaviour. 
If one wishes to apply the TTM to weight control and diabetes management, the best approach is to choose one or more specific behavioural goals likely to improve outcome (e.g. exercise at least three times per week, consumption of less than a specified number of servings per day from a list of high-energy foods; a specified frequency of glucose self-monitoring) (Curry, 1993). Clearly, people will be at different stages of readiness for adhering to different aspects of, for example, a diabetes management regimen (Ruggiero \& Prochaska, 1993), or a weight-control programme. Identification of the stage of readiness for adopting various aspects of a programme can enable a focus on different intervention strategies for different aspects of management. If people are encouraged to focus first on an aspect of a regimen for which they are most ready to consider change, they are more likely to experience success and improved self-efficacy. Movement along the stages for individual behaviours can also provide a more encouraging means of monitoring success, rather than focusing only on outcomes such as body weight.

\section{Criticisms of the transtheoretical model}

The TTM has attracted a number of criticisms. Bandura (1997) described human functioning as too multifaceted and multidetermined to be categorized into a few discrete stages. For example, he comments that classifying people as precontemplators provides no explanation for why they do not consider making changes. The stage variable, although having received the greatest attention of any aspect of the model, is only one of a much larger number of constructs used to account for intentional behaviour change (Prochaska \& Velicer, 1997). Indeed no one has ever claimed that stage assignment itself explains why someone is or is not taking action.

Rejection of the model by Farkas et al. (1996) is also based on an analysis of only one of the model's many constructs: the stage construct. A single variable is not a theory, and cannot possibly explain the process of behaviour change. Furthermore, several of the commentaries on that paper (in the same journal issue) have emphasized how 'competitive framing' by Farkas $e t$ al. (1996) of different models does little to shed light on the process of behaviour change (Shiffman, 1996). A comparison between a single variable drawn from the TTM and multiple variables cannot possibly amount to a reasonable test of the model: multiple variables can almost always account for more variance in future behaviour than a single variable. Furthermore, Farkas et al. (1996) develop what is essentially a predictive model for smoking cessation and, unlike the TTM, their model provides no explanation or understanding of why their predictors are important in explaining future behaviour. Nor do their findings have any implications for how to develop more effective interventions. Farkas et al. (1996) show that smokers who have quit in the past are more likely to quit in the future, but this is of little value unless we know why. In seeking an explanation, Sutton (1996) comments that is it difficult not to refer to concepts such as motivation, self-efficacy, and stage of readiness to change.

In contrast, Jeffery et al. (1999) acknowledge that their focus on 'stage' alone means that they are not assessing the validity of the TTM. However, they argue that the failure of their simple stage classification scheme to predict future outcome calls into question 'the generality of the stages of change classification system across behavioural domains'. The crucial flaw in this study design lies in hypothesizing that stage of readiness 'to diet' should predict not future behaviour, but weight change over 3 years. Models of behaviour should only be used to examine behaviour, not physiological outcomes determined by multiple behaviours, only one of which is referred to in vague terms in the staging algorithm of Jeffery et al. (1999). 
Another criticism by Bandura (1997) is that a genuine stage theory involves qualitative transformations across stages, an invariant sequence of stages (i.e. stages cannot be skipped) and non-reversibility (i.e. no recycling occurs). This view appears to be at odds with other stage theories, in which it is assumed that people can and do return to earlier stages or can skip stages (Prochaska \& Velicer, 1997) and with the defining characteristics outlined by Weinstein et al. (1998). Bandura (1997) argues that 'stage thinking' would 'constrain the scope of interventions to promote change', since for precontemplators, the 'prescription for change emphasizes the need to alter their outcome expectations'. This, however, is only one of the approaches used by TTM-researchers in order to stimulate movement from precontemplation.

The fact that the divergent behaviour change prescriptions of Freudian, Skinnerian or existential theories are believed by some of their proponents to be contradictory and incompatible (Bandura, 1997), does not mean, Prochaska \& Velicer (1997) argue, that this is necessarily the case. Self-changers, in fact, successfully change using a whole range of such strategies. It makes little sense to suggest that because stimulus control and countering faulty beliefs arise from different psychotherapeutic approaches, that they cannot usefully be integrated in one model.

In practical applications to the development and evaluation of nutrition interventions, TTM approaches can be combined with approaches from other behavioural theories. For example, in stage-matched exercise intervention programmes, Marcus et al. (1999) have also drawn on social cognitive theory and decision making in the preparation of stage-specific self-help manuals. Campbell et al. (1994) structured their tailored messages according to a framework based on the TTM and the health belief model. These different theories or models of behaviour can be thus be viewed as complementary rather than conflicting. However, when the production of tailored materials draws on a number of theories or models of behaviour, it is impossible to identify whether the superior efficacy of a tailored intervention is associated with constructs from other theories rather than stage per se (Marcus et al. 1999).

Even though stage-matched interventions can provide tailored material to entire populations, TTM-based interventions may be criticized for addressing problematic health behaviours mainly as an individual problem. That is, they focus on the motivations, perceptions and processes of individuals. However, powerful intervention combinations may be produced by combining individualized TTM-based interventions with interventions aimed at creating environments supportive of healthier behaviours. Since applications of the TTM to promotion of organizational change are currently being explored (D Levesque, personal communication), the model may be useful in promoting change in worksite and school environments.

\section{Conclusions}

If we accept one of the simplest defining characteristics of stage theories put forward by Weinstein et al. (1998), that a stage theory requires an accurate classification system for assigning each individual to only one stage, we must question the appropriateness of goals which are unclear to participants (such as dietary fat reduction or increased fibre intake) as applications of the TTM. The continuing methodological difficulties encountered by researchers working with these goals suggests that perhaps other dietary applications are more suitable. Essentially the model is concerned with people's behaviour change, yet fat and fibre consumption are not behaviours which people engage in: they are nutritional outcomes of a complex collection of eating behaviours. Perhaps future applications of the model would do better to focus on actual eating behaviours, such as the five-a-day recommendation for fruit and 
vegetable consumption. With such goals, the evidence suggests that accurate systems that can classify everyone into just one stage are possible. There are in fact several ongoing projects to promote greater fruit and vegetable consumption that are using the TTM approach (Campbell et al. 1998).

Another clear need is for more research on the whole model, rather than on single constructs such as the stages of change. The demonstration of an association between stage and nutrient or food group intake confirms the value of stage as a marker of intake, but is not sufficient to demonstrate the validity of the model. There is a particular paucity of research on the processes of eating behaviour change. Of the very few studies which appear to fulfil Weinstein's first criterion (e.g. Gulliver, 1998; Ling \& Horwath, 1999a,b; A Ling and CC Horwath, unpublished results), only one cross-sectional study has included the whole model (stage, processes, self-efficacy, decisional balance) (Horwath \& Gulliver, 1998). The study, has, however, confirmed remarkably similar patterns of change across the stages in the various model constructs to those observed for smoking cessation. There is also some support for the requirement that different factors are important at different stages (Ling, 1999; Sporny \& Contento, 1999).

Prospective studies and stage-matched interventions examining TTM hypotheses for dietary change are sparse. Yet only longitudinal research can truly convince us that the TTM is valid for eating behaviour change. In order to conduct such studies, there is a need for valid questionnaires to measure all aspects of the model. Most dietary applications of the TTM are concerned with the nutritional outcome of dietary fat reduction and all of the small number of prospective studies identified deal with either this goal or the even more complex goal of weight control.

Cross-sectional analyses generally support the predicted patterns of between-stage differences in processes, self-efficacy and decisional balance for those dietary goals examined. It must be emphasized, however, that simple cross-sectional comparisons of the characteristics of people classified into different stages are not the most powerful approach if we are interested in testing the validity of the TTM. Investigators of eating behaviour change who choose crosssectional designs should focus on careful validation of questionnaires, whether patterns of between-stage differences vary from one predictor variable to another, and whether different factors are important in distinguishing different stages.

So, in response to the question; 'does eating behaviour change follow a stage process?', as yet, it appears there is no conclusive answer. The research on dietary applications of the TTM is limited and much of it is hampered by a number of methodological difficulties, not least of which is a focus on complex nutritional goals. The effectiveness of the model as a guide for developing smoking cessation and exercise acquisition (Marcus et al. 1999) programmes, and the evidence so far available on dietary applications, however, are sufficiently encouraging to warrant the inclusion of TTM constructs in prospective studies as well as further studies to evaluate the efficacy of stage-matched interventions relative to standardized approaches to promoting eating behaviour change. Only one published stage-matched dietary intervention study has been identified (Campbell et al. 1994), and yet such studies will provide the ultimate test of the model in relation to dietary change. It is therefore important to explore the requirements of such intervention studies.

\section{Future directions: designing stage-matched tailored dietary interventions}

Three crucial requirements for the design of stage-matched interventions are: (1) that people can be correctly classified according to stage; (2) a good understanding of the factors associated 
with different stage transitions for the behaviour of interest; (3) means are available to modify the factors identified as being important in the various stage transitions.

TTM ideas and approaches can undoubtedly be employed in interpersonal counselling situations (Miller \& Rollnick, 1991), and may enhance the effectiveness of dietitians' interaction with clients. Interpersonal couselling, however, is expensive and time-consuming since trained counsellors and person-to-person or small group sessions are required. The population shifts in eating behaviour required for disease prevention cannot realistically be accomplished in this way.

One of the greatest strengths of the TTM approach, clearly demonstrated in the smoking cessation intervention studies (Prochaska et al. 1993), is that a huge impact can be made with the target population by: (1) contacting large random samples of the population by randomdigit-dialling (or random mailouts) to identify those with the problem behaviour (i.e. smokers) and inviting all smokers to participate in a study which addresses relevant issues for those at all stages; (2) subsequently delivering personalized, tailored materials for smokers at all stages of change, where messages are tailored not only to the person's stage of readiness to change, but also to their level of process use, decisional balance and self-efficacy. Tailoring of messages to such an extent can only be realistically achieved through use of computer expert-system technology.

Using this approach, 82-85\% of the entire target group (JO Prochaska, WF Velicer, J Fava and J Rossi, unpublished results), predominantly precontemplators, can be recruited into stagematched intervention programmes. This contrasts strikingly with the low participation rates typically found with action-oriented approaches. For example, a widely publicized free actionoriented self-help programme resulted in only $4 \%$ of smokers signing up despite a year of recruitment (Orleans et al. 1998). The Minnesota Heart Health programme randomly assigned individuals to various recruitment strategies, including personalized letters about home-based programmes for smoking cessation and weight loss, and achieved recruitment rates of 1-5\% and 3-12\% respectively (Schmid et al. 1989). Combined with the greater efficacy of the stagematched approach compared with standardized intervention approaches (Prochaska et al. 1993), high recruitment rates result in programmes which achieve an overall impact (recruitment rate $\times$ efficacy of intervention) rarely, if ever, equalled elsewhere.

No studies have so far been published which evaluate such a comprehensive approach with eating behaviour change, although long-term studies are currently underway at the University of Rhode Island Cancer Prevention Research Centre to examine stage-matched interventions for dietary fat reduction (G Greene, personal communication).

Perhaps one of the greatest contributions of the TTM smoking cessation research is the development of approaches which are effective in communicating with, recruiting and retaining precontemplators: the group usually overlooked or assumed too resistant to involve in traditional health promotion efforts. Prochaska et al. (1997) have been able to retain precontemplative smokers at the same high level as those who started in the preparation stage.

In order to be appropriate for use in large-scale campaigns, accurate stage classification must be able to be achieved rapidly and efficiently, thus presumably via a self-administered instrument. Some of the most accurate stage classification systems so far available for eating behaviour goals have depended for their success on interaction between respondent and interviewer to clarify both current and goal behaviours (Horwath \& Gulliver, 1998; Ling \& Horwath, 1999b). Further work is required to achieve accurate self-administered stage-classification methods for dietary goals. Due to the more complex nature of eating behaviour goals compared with smoking cessation, this may present one of the greatest challenges in the progress towards stage-matched dietary interventions. 
An important question deserving further research is the extent of tailoring which is required in order to achieve significant improvements in efficacy over standardized interventions. Smoking-cessation researchers argue the need to individually tailor on the basis of all TTM constructs for maximum efficacy (Prochaska et al. 1993). However, the development of sophisticated computer expert-systems for each behaviour goal of interest would often be prohibitively expensive and time-consuming. Setting up such expert systems is impossible in the absence of considerable data on the population norms for each of the model constructs for the target group of interest and requires short validated instruments to assess stage, processes, decisional balance and self-efficacy. Campbell et al. (1994) achieved significant dietary fat reduction by individually computer tailoring materials to stage, current dietary intake, motives, barriers, beliefs and self-efficacy. Successful physical activity interventions have been achieved more simply by tailoring to stage using five stage-specific self-help manuals (Marcus et al. 1999). The relative efficacy for eating behaviour change of simple stage-matched manuals compared with more individualized computer tailoring is unknown.

The nature of the comparison intervention also requires consideration. If nutrition educators are to adopt a stage approach more widely, we need to establish not only that stagematched dietary interventions promote more change than would occur in a control group receiving no intervention, but whether they indeed outperform our currently best available standardized materials.

An exciting opportunity for stage-model researchers is the design of nutrition interventions whereby individuals may access tailored materials via the Internet. Although such an approach would undoubtedly miss precontemplators, it could present an economical way to provide effective nutrition messages to all those with Internet access. Such programmes could reach people in their own homes, in schools or in the workplace.

Interventionists need not, however, be limited in their production of stage-matched materials to print media. Being aware of different learning styles, literacy levels and preferences, stage-matched nutrition materials may also take the form of audiotapes, videotapes, or pictorial reminders. Creative interventions to test the effectiveness of stage-matched approaches involving varying degrees of tailoring and carefully evaluated over longer time periods are required.

\section{Acknowledgements}

Grateful thanks to Professors Mary Story and Dianne Neumark-Sztainer in Public Health Nutrition at the University of Minnesota for helpful comments on this manuscript and to Dr Allan Blackman for careful proof-reading.

\section{References}

Ajzen I \& Madden TJ (1986) Prediction of goal-directed behaviour: attitudes, intentions and perceived behavioural control. Journal of Experimental \& Social Psychology 22, 453-474.

Auld GW, Nitzke SA, McNulty J, Bock MA, Bruhn CM, Gabel K, Lauritzen G, Lee YF, Medeiros D, Newman R, Ortiz M, Read M, Schutz H \& Sheehan E (1998) A stage-of-change classification system based on actions and beliefs regarding dietary fat and fiber. American Journal of Health Promotion 12, 192-201.

Bandura A (1986) Social Foundations of Thought and Action: A Social Cognitive Theory. Englewood Cliffs, NJ: Prentice-Hall. 
Bandura A (1997) The anatomy of stages of change. American Journal of Health Promotion 12, 8-10.

Beresford SAA, Curry SJ, Kristal AR, Lazovich D, Feng Z \& Wagner EH (1997) A dietary intervention in primary care practice: The eating patterns study. American Journal of Public Health 87, 610-616.

Bettman JR (1979) An Information Processing Theory of Consumer Choice. Reading, MA: Addison-Wesley.

Birkett NJ \& Boulet J (1995) Validation of a food habits questionnaire: poor performance in male laborers. Journal of the American Dietetic Association 95, 558-563.

Birkett NJ, Hotz SC \& Allston J (1993) Dietary fat reduction: Challenges in applying the stages of change model. Presented at the First International Heart Health Conference, Victoria, BC.

Block G, Hartmann AM, Dresser CM, Carroll MD, Gannon J \& Gardner LA (1986) A data-based approach to diet questionnaire design and testing. American Journal of Epidemiology 124, 453.

Bowen DJ, Meischke H \& Tomoyasu N (1994) Preliminary evaluation of the processes of changing to a low fat diet. Health Education Research 9, 85-94.

Brug J, Glanz K \& Kok G (1997) The relationship betwen self-efficacy, attitudes, intake compared to others, consumption, and stages of change related to fruit and vegetables. American Journal of Health Promotion 12, $25-30$.

Brug J, Glanz K, Van Assema P, Kok G \& van Breukelen GJP (1998a) The impact of computer-tailored feedback and iterative feedback on fat, fruit and vegetable intake. Health Education \& Behaviour 25, 517-531.

Brug J, Steenhuis IHM, Van Assema P \& De Vries H (1996) The impact of a computer-tailored nutrition intervention. Preventive Medicine 25, 236-342.

Brug J, Steenhuis IHM, Van Assema P, Glanz K \& De Vries H (1998b) The impact of two computer-tailored nutrition education interventions. Health Education Research 13, 1-11.

Brug J, Van Assema P, Lenderink T, Glanz K \& Kok G (1994) Self-rated dietary fat intake: association with objective assessment of fat, psychosocial factors and intention to change. Journal of Nutrition Education 26, 218-223.

Campbell MK, DeVellis B, Strecher V, Ammerman A, DeVellis R \& Sandler R (1994) Improving dietary behaviour: The effectiveness of tailored messages in primary care settings. American Journal of Public Health 84, $783-787$.

Campbell MK, Reynolds KD, Havas S, Curry S, Bishop D, Nicklas T, Palombo R, Buller D, Feldman R, Topor M, Johnson C, Beresford SAA, Motsinger BM, Morrill C \& Heimendinger J (1999) Stages of change for increasing fruit and vegetable consumption among adults and young adults participating in the national 5-a-day for better health community studies. Journal of Health Education \& Behaviour 26, 513-534.

Campbell MK, Symons M, Demark-Wahnefried W, Polhamus B, Bernhardt JM, McClelland JW \& Washington C (1998) Stages of change and psychosocial correlates of fruit and vegetable consumption among rural AfricanAmerican church members. American Journal of Health Promotion 12, 185-191.

Curry SJ (1993) Commentary: In search of how people change: applications to addictive behaviours. Diabetes Spectrum: From Research to Practice 6, 10-14.

Curry SJ, Kristal AR \& Bowen DJ (1992) An application of the stage model of behaviour change to dietary fat reduction. Health Education Research 7, 494-503.

de Graaf C, Van der Gaag M, Kafatos A, Lennernas M \& Kearnery JM (1997) Stages of dietary change among nationally representative samples of adults in the European Union. European Journal of Clinical Nutrition 51, Suppl. 2, S47-S56.

DiClemente CC (1981) Self efficacy and smoking cessation maintainance: A preliminary report. Cognitive Therapy and Research 5, 175-187.

DiClemente CC \& Prochaska JO (1982) Self-change and therapy change of smoking behaviour. A comparison of processes of change in cessation and maintenance. Addictive Behaviour 7, 133-142.

DiClemente CC, Prochaska JO \& Gilbertini M (1985) Self-efficacy and the stages of self-change in smoking. Cognitive Therapy and Research 9, 181-200.

Domel SB, Baranowski T, Davis HC, Thompson WO, Leonard SB \& Baranowski J (1996) A measure of stages of change in fruit and vegetable consumption among fourth and fifth grade school children: reliability and validity. Journal of the American College of Nutrition 15, 56-64.

Farkas AJ, Pierce JP \& Zhu S-H (1996) Addiction versus stages of change models in predicting smoking cessation. Addiction 91, $1271-1280$.

Glanz K \& Eriksen MP (1993) Individual and community models for dietary behaviour change. Journal of Nutrition Education 25, 80-86.

Glanz K, Kristal AR, Tilley BC \& Hirst K (1998a) Psychosocial correlates of healthful diets among male auto workers. Cancer Epidemiology, Biomarkers and Prevention 7, 119-126.

Glanz K, Patterson RE, Kristal AR, DiClemente CC, Heimendinger J, Linnan L \& McLerran D (1994) Stages of change in adopting healthy diets: fat, fibre and correlates of nutrient intake. Health Education Quarterly 21, 499-519.

Glanz K, Patterson RE, Kristal AR, Feng Z, Linnan L, Heimendinger J \& Hebert JR (1998b) Impact of work site health promotion on stages of dietary change: The working well trial. Health Education and Behaviour 25, 448-463.

Glanz K \& Rimer BK (1997) Theory at a Glance: A Guide for Health Promotion Practice. Washington, DC: US Dept of Health and Human Services Public Health Service, National Institutes of Health.

Greene GW \& Rossi SR (1998) Stages of change for reducing dietary fat intake over 18 months. Journal of the American Dietetic Association 98, 529-534.

Greene GW, Rossi SR \& Reed GR (1993) The effect of feedback on dietary intent to reduce fat intake. Topics in Clinical Nutrition 9, 20-28. 
Greene GW, Rossi SR, Reed GR, Willey C \& Prochaska JO (1994) Stages of change for dietary fat reduction to $30 \%$ of calories or less. Journal of the American Dietetic Association 94, 1105-1110.

Gulliver P (1998) Development and validation of scales to measure dimensions of the Transtheoretical Model for increasing milk product intake in women. $\mathrm{PhD}$ Thesis, University of Otago, Dunedin, New Zealand.

Herrick AB, Stone WJ \& Mettler MM (1997) Stages of change, decisional balance, and self-efficacy across four health behaviours in a worksite environment. American Journal of Health Promotion 12, 49-56.

Horwath CC \& Gulliver P (1998) The challenge of behaviour change. New Zealand Science Monthly 9, 8-9.

Janz NK \& Becker MH (1984) The health belief model: A decade later. Health Education Quarterly 11, 1-47.

Jeffery RW, French SA \& Rothman AJ (1999) Stage of change as a predictor of success in weight control. Health Psychology (In the Press).

Kreuter MW \& Strecher VJ (1996) Do tailored behaviour change messages enhance the effectiveness of health risk appraisal? Results from a randomised trial. Health Education Research 11, 97-105.

Kristal AR, SeLett AC, Henry AJ \& Fowler AS (1990) Rapid assessment of dietary intake of fat, fiber and saturated fat. Validity of an instrument suitable for community intervention research and nutritional surveillance. American Journal of Health Promotion 4, 288-295.

Laforge RG, Greene GW \& Prochaska JO (1994) Psychoscial factors influencing low fruit and vegetable consumption. Journal of Behavioral Medicine 17, 361-374.

Lamb R \& Joshi MS (1996) The stage model and processes of change in dietary fat reduction. Journal of Human Nutrition and Dietetics 9, 43-53.

Ling AM (1999) Stages of change, self-efficacy and decisional balance for the fruit, vegetables and grains dietary guidelines: A random population study of Chinese Singaporeans. PhD Thesis, University of Otago.

Ling A \& Horwath CC (1999a) Self-efficacy and consumption of fruit and vegetables: validation of a summated scale. American Journal of Health Promotion 13, 290-298.

Ling AM \& Horwath CC (1999b) Design and validation of stage of change algorithms for fruit, vegetable and grain recommendations among Chinese Singaporeans. Journal of the American Dietetic Association (In the Press).

McConnaughy EA (1989) Stages of change in psychotherapy: A follow-up report. Psychotherapy 26, 494-503.

Marlatt GA (1982) Relapse prevention: A self-control program for the treatment of addictive behaviours. In Adherence, Compliance and Generalization in Behavioral Medicine [RB Stuart, editor]. New York: Brunner/Mazel, Inc.

Marcus BH, Emmons KM, Simkin-Silverman L, Linnan LA, Taylor ER, Bock BC, Roberts MB, Rossi JS \& Abrams DB (1999) Evaluation of motivationally-tailored versus standard self-help physical activity interventions at the workplace. American Journal of Health Promotion (In the Press).

Marcus BH, Rossi JS, Selby VC, Niaura RS \& Abrams DB (1992) The stages and processes of exercise adoption and maintenance in a worksite sample. Health Psychology 11, 386-395.

Miller WR \& Rollnick S (1991) Motivational Interviewing: Preparing People to Change Addictive Behavior. New York: Guilford Press.

Ni Mhurchu C, Margetts BM \& Speller VM (1997) Applying the Stages-of-Change model to dietary change. Nutrition Reviews 55, 10-16.

O'Connell D \& Velicer WF (1998) A decisional balance measure and the stages of change model for weight loss. International Journal of Addiction 23, 729-750.

Orleans CT, Schoenbach VJ \& Salmon MA (1988) Effectiveness of self-help quit smoking strategies. Four National Cancer Institute-funded self-help smoking cessation trials: Interim results and emerging patterns. Annual meeting of the Association for the Advancement of Behavior Therapy, New York. Washington DC: National Cancer Institute.

Ounpuu S (1997) Methodological considerations for applications of the Transtheoretical Model to dietary fat reduction. PhD Thesis, University of Guelph.

Ounpuu S, Woolcott DM \& Greene GW (1999a) Precontemplation or maintenance? Defining stage of change for lower fat eating. Journal of the American Dietetic Association (In the Press).

Ounpuu S, Woolcott DM \& Rossi SR (1999b) Self efficacy as an intermediate outcome variable in the Transtheoretical Model: Validation of a measurement model for applications to dietary fat reduction. Journal of Nutrition Education (In the Press).

Prochaska JO (1979) Systems of Psychotherapy: A Transtheoretical Analysis. Pacific Grove, CA: Brooks-Cole.

Prochaska JO (1991) Assessing how people change. Cancer 67, 805-807.

Prochaska JO \& DiClemente CC (1983) Stages and processes of self-change of smoking: toward an integrative model of change. Journal of Consulting \& Clinical Psychology 51, 390-395.

Prochaska JO \& DiClemente C (1985) Common processes of change in smoking, weight control and psychological distress. In Coping and Substance Use: A Conceptual Framework, pp. 345-363 [S Shiffman and T Wills, editors]. New York: Academic Press.

Prochaska JO, DiClemente CC \& Norcross JC (1992a) In search of how people change: Applications to addictive behaviors. American Psychologist 47, 1102-1114.

Prochaska JO, DiClemente CC, Velicer W, Ginpil S \& Norcross JC (1985) Predicting change in smoking status for self changers. Addictive Behaviors 10, 395-406.

Prochaska JO, Norcross JC, Fowler JL, Follick MJ \& Abrams DB (1992b) Attendence and outcome in a work site weight control program: Processes and stages of change as process and predictor variables. Addictive Behaviors 17, $35-45$. 
Prochaska JO, Velicer WF, DiClemente CC \& Fava J (1988) Measuring the processes of change: Applications to the cessation of smoking. Journal of Consulting and Clinical Psychology 56, 520-528.

Prochaska JO, Redding C \& Evers K (1997) The Transtheoretical Model of Behavior Change. In Health Behavior and Health Education: Theory, Research and Practice, 2nd ed. pp. 60-84 [K Glanz, FM Lewis and BK Rimer, editors]. San Francisco, CA: Jossey-Bass.

Prochaska JO \& Velicer WF (1997) Misinterpretations and misapplications of the Transtheoretical Model. American Journal of Health Promotion 12, 11-12.

Prochaska JO, Velicer WF, DiClemente CC \& Rossi JS (1993) Standardised, individualised, interactive and personalised self-help programs for smoking cessation. Health Psychology 12, 399-405.

Prochaska JO, Velicer WF, Guadagnali E, Rossi JS \& DiClemente CC (1991) Patterns of change: dynamic typology applied to smoking cessation. Multivariate Behavioral Research 26, 83-107.

Prochaska JO, Velicer WF, Rossi JS, Goldstein MG, Marcus BH, Rakowski W, Fiore C, Harlow LL, Redding CA, Rosenblom D \& Rossi SR (1994) Stage of change and decisional balance for 12 problem behaviors. Health Psychology 13, 39-46.

Rossi JS (1992a) Stages of change for 15 health risk behaviours in an HMO population. Paper presented at the 13th annual meeting of the Society for Behavioural Medicine, New York.

Rossi JS (1992b) Common processes of change across nine problem behaviours. Paper presented at the 100th annual convention of the American Psychological Association, Washington, DC.

Rossi JS, Blais LM, Redding CA \& Weinstock MA (1995a) Preventing skin cancer through behaviour change: Implications for interventions. Dermatologic Clinics 13, 613-622.

Rossi JS, Marcus BH, Rossi SR, Snow MG, Velicer WF \& Prochaska JO (1991a) Processes of change for smoking, exercise, weight and alcohol abuse. Paper presented at the 99th annual convention of the American Psychological Association, San Francisco, CA.

Rossi JS, Rossi SR, Velicer WF \& Prochaska JO (1995b) Motivational readiness to control weight. In Handbook of Assessment Methods for Eating Behaviours and Weight-related Problems: Measures, Theory and Research, pp. 387430 [DB Allison, editor]. Thousand Oaks, CA: Sage.

Rossi SR (1993) Dietary fat reduction behavior profiles across five categories of high fat food sources for five stages of change. Paper presented at the 13th annual meeting of the Society for Behavioral Medicine, San Francisco, CA.

Rossi SR, Greene GW, Reed G \& Prochaska JO (1993a) A comparison of four stage of change algorithms for dietary fat reduction. Annals of Behavioral Medicine 15, (Suppl.), A63.

Rossi SR, Greene GW, Reed G, Prochaska JO \& Velicer WF (1994b) Continued investigation of a processes of change measure for dietary fat reduction. Paper presented at the 14th annual convention of the Society for Behavioral Medicine, Boston, MA.

Rossi SR, Reed G, Greene GW, Rossi JS, Prochaska JO \& Velicer WF (1994a) Development of a self-efficacy questionnaire for dietary fat reduction. Paper presented at the 14th annual convention of the Society for Behavioral Medicine, Boston, MA.

Rossi SR, Reed G, Greene GW, Rossi JS, Prochaska JO \& Velicer WF (1994c) Cross validation of a decisional balance measure for dietary fat reduction. Paper presented at the 14th annual convention of the Society for Behavioral Medicine, Boston, MA.

Rossi SR \& Rossi JS (1993) Processes of change for dietary fat reduction. Paper presented at the 13th annual convention of the Society for Behavioral Medicine, San Francisco, CA.

Rossi SR, Rossi JS \& Prochaska JO (1991b) Processes of change for weight control: a follow up study. Paper presented at the 99th Annual Convention of the American Psychological Association, San Francisco, CA.

Rossi SR, Rossi JS, Prochaska JO \& Velicer WF (1993b) Measurement structure of a decisional balance questionnaire for dietary fat reduction. American Psychological Association, Toronto, Canada.

Rossi SR, Rossi JS, Rossi-Del Prete LM, Prochaska JO, Branspach SW \& Carlton RH (1994d) A process of change model for weight control for participants in community based weight loss programmes. International Journal of the Addictions 29, 161-177.

Ruggiero L \& Prochaska JO (1993) Readiness for change: application of the Transtheoretical Model to diabetes. Diabetes Spectrum: From Research to Practice 6, 21-60.

Safer MA, Tharps Q, Jackson T \& Leventhal H (1979) Determinants of three stages of delay in seeking care at a medical clinic. Medical Care 17, 11-29.

Schmid TL, Jeffery RW \& Hellerstedt WL (1989) Direct mail recruitment to house-based smoking and weight control program: A comparison of strengths. Preventive Medicine 18, 503-517.

Schwarzer R (1992) Self-efficacy in the adoption and maintenance of health behaviors: theoretical approaches and a new model. In Self-efficacy: Thought Control of Action, pp. 217-243 [R Schwarzer, editor]. Washington, DC: Hemisphere.

Shiffman S (1996) "Addiction versus stages of change models" vs. "Addiction and stages of change models". Addiction 91, 1289-1290.

Sigman-Grant M (1996) Stages of change: A framework for nutrition interventions. Nutrition Today 31, 162-170.

Sorensen G, Stoddard A \& Macario E (1998) Social support and readiness to make dietary changes. Health Education \& Behaviour 25, 586-598.

Sporny LA \& Contento IR (1995) Stages of change in dietary fat reduction: Social psychological correlates. Journal of Nutrition Education 27, 191-199. 
Stafleu A, de Graaf C, van Staveren WA \& Schroots JJ (1991/2) A review of selected studies assessing socialpsychological determinants of fat and cholesterol intake. Food Quality \& Preferences 3, 183-200.

Steptoe A, Wijetunge S, Doherty S \& Wardle J (1996) Stages of change for dietary fat reduction and associations with food intake, decisional balance and motives for food choice. Health Education Journal 55, 108-122.

Sutton S (1996) Further support for the stages of change model? Addiction 91, 1287-1289.

Velicer WF, DiClemente CC, Prochaska JO, Abrams DB, Emmons KM \& Pierce JP (1995) Distribution of smokers by stage in three representative samples. Preventive Medicine 24, 401-411.

Velicer WF, DiClemente CC, Prochaska JO \& Brandenberg N (1985) Decisional balance measure for assessing and predicting smoking status. Journal of Personality and Social Psychology 48, 1279-1289.

Velicer WF, DiClemente CC, Rossi JS \& Prochaska JO (1990) Relapse situations and self-efficacy: an integrative model. Addictive Behaviors 15, 271-283.

Weinstein ND, Rothman AJ \& Sutton SR (1998) Stage theories of health behaviour: conceptual and methodological issues. Health Psychology 17, 290-299.

Weinstein ND \& Sandman PM (1992) A model of the precaution adoption process: evidence from home radon testing. Health Psychology 11, 170-180. 